- Article type: Research paper

- Date text written: March 2014

- Number of words in main text: 5090; tables:6; figures: 21

\title{
Dynamic Response of Flexible Square Tunnels: Centrifuge Testing and Validation of Existing Design Methodologies
}

Author 1

- Grigorios Tsinidis, Civil Engineer, MSc, PhD Candidate

- Department of Civil Engineering, Aristotle University, Thessaloniki, Greece

Author 2

- Kyriazis Pitilakis, Professor

- Department of Civil Engineering, Aristotle University, Thessaloniki, Greece

Author 3

- Gopal Madabhushi, Professor

- Schofield Centre, University of Cambridge, Cambridge, UK

Author 4

- Charles Heron, Research Associate

- Schofield Centre, University of Cambridge, Cambridge, UK

Full contact details of corresponding author.

Grigorios Tsinidis, Civil Engineer, MSc, PhD Candidate

Department of Civil Engineering, Research Unit of Geotechnical Earthquake Engineering and Soil Dynamics, Aristotle University of Thessaloniki, PO BOX 424 GR-54124, Thessaloniki, Greece, tel: +302310994208, e-mail: gtsinidi@civil.auth.gr 
A series of dynamic centrifuge tests were performed on flexible aluminum square tunnel models embedded in Hostun dry sand. The tests were carried out at the centrifuge facility of the University of Cambridge in order to further improve our knowledge on the seismic response of rectangular embedded structures and to calibrate currently available design methods. The soiltunnel system response was recorded with an extensive instrumentation array, comprising of miniature accelerometers, pressure cells and position sensors in addition to strain gauges, which recorded the tunnel lining internal forces. Full dynamic time-history analysis of the coupled soil-tunnel system was performed for a representative set of experimental tests. Numerical predictions are compared to the experimental data to validate the effectiveness of the numerical modeling. The interpretation of both numerical and experimental results reveals, among others: (i) a rocking response of the model tunnel in addition to classical racking, (ii) residual earth pressures on the tunnel side walls and (iii) residual internal forces after shaking, which are amplified with the tunnel's flexibility. Finally the calibrated numerical models are used to validate the accuracy of simplified design methods used in engineering practice.

\section{Keywords chosen from ICE Publishing list}

Tunnels \& tunneling; centrifuge modeling; earthquakes; numerical modeling; soil/structure interaction

\section{List of notation}

$2|\Delta M| \quad$ lining bending moment dynamic increment

$2|\Delta N| \quad$ lining axial force dynamic increment

a input motion amplitude

$a_{f f} \quad$ free field horizontal acceleration

$\mathrm{AH} \quad$ air hammer test

$B \quad$ tunnel width

$d_{10} \quad$ sand grain diameter at $10 \%$ passing

$d_{50} \quad$ sand grain diameter at $50 \%$ passing

$d_{60} \quad$ sand grain diameter at $60 \%$ passing

e sand void ratio

$e_{\max } \quad$ maximum sand void ratio

$e_{\min } \quad$ minimum sand void ratio 


\begin{tabular}{|c|c|c|}
\hline 1 & $E$ & aluminum alloy Young's modulus \\
\hline $\begin{array}{l}2 \\
3\end{array}$ & $E_{c}$ & concrete Young's modulus \\
\hline $\begin{array}{l}4 \\
5\end{array}$ & $f$ & input motion dominant frequency \\
\hline $\begin{array}{l}6 \\
7\end{array}$ & $F$ & soil to tunnel flexibility ratio \\
\hline $\begin{array}{l}8 \\
9\end{array}$ & $f_{b k}$ & aluminum alloy tensile strength \\
\hline $\begin{array}{l}10 \\
11\end{array}$ & $F_{\text {inertia }}$ & equivalent inertial load \\
\hline $\begin{array}{l}12 \\
13\end{array}$ & $G$ & reduced sand shear modulus \\
\hline $\begin{array}{l}14 \\
15\end{array}$ & $G_{\max }$ & small strain sand shear modulus \\
\hline $\begin{array}{l}16 \\
17\end{array}$ & $H$ & tunnel height \\
\hline $\begin{array}{l}18 \\
19\end{array}$ & $K_{0}$ & earth coefficient at rest \\
\hline $\begin{array}{l}20 \\
21\end{array}$ & $L$ & length \\
\hline $\begin{array}{l}22 \\
23\end{array}$ & $M$ & mass \\
\hline $\begin{array}{l}24 \\
25\end{array}$ & $N$ & scale factor \\
\hline $\begin{array}{l}26 \\
27\end{array}$ & $P$ & equivalent to the tunnel racking distortion force \\
\hline 28 & & \\
\hline $\begin{array}{l}29 \\
30\end{array}$ & $R$ & racking ratio \\
\hline $\begin{array}{l}30 \\
31\end{array}$ & $R C$ & resonant column tests \\
\hline $\begin{array}{l}32 \\
33\end{array}$ & & \\
\hline $\begin{array}{l}33 \\
34\end{array}$ & $T$ & time \\
\hline $\begin{array}{l}35 \\
36\end{array}$ & $T X$ & cyclic triaxial tests \\
\hline $\begin{array}{l}37 \\
38\end{array}$ & $v$ & aluminum alloy Poisson ratio \\
\hline $\begin{array}{l}38 \\
39\end{array}$ & $\alpha$ & mean reduction coefficient for sand shear modulus during shaking \\
\hline $\begin{array}{l}40 \\
41 \\
42\end{array}$ & V & aluminum alloy unit weight \\
\hline 43 & $\delta$ & horizontal deformation at soil surface \\
\hline $\begin{array}{l}45 \\
46\end{array}$ & $\Delta_{f f}$ & ground racking distortion \\
\hline $\begin{array}{l}47 \\
48\end{array}$ & $\Delta_{\text {str }}$ & tunnel racking distortion \\
\hline $\begin{array}{l}49 \\
50\end{array}$ & $\mu$ & soil-tunnel interface friction coefficient \\
\hline $\begin{array}{l}51 \\
52\end{array}$ & $\rho_{s}$ & sand density \\
\hline $\begin{array}{l}53 \\
54\end{array}$ & $\sigma^{\prime}$ & mean effective stress \\
\hline $\begin{array}{l}55 \\
56\end{array}$ & $\sigma$ & dynamic earth pressure \\
\hline $\begin{array}{l}57 \\
58\end{array}$ & $T$ & dynamic shear stress \\
\hline 59 & $\varphi_{c v}$ & sand critical friction angle \\
\hline
\end{tabular}




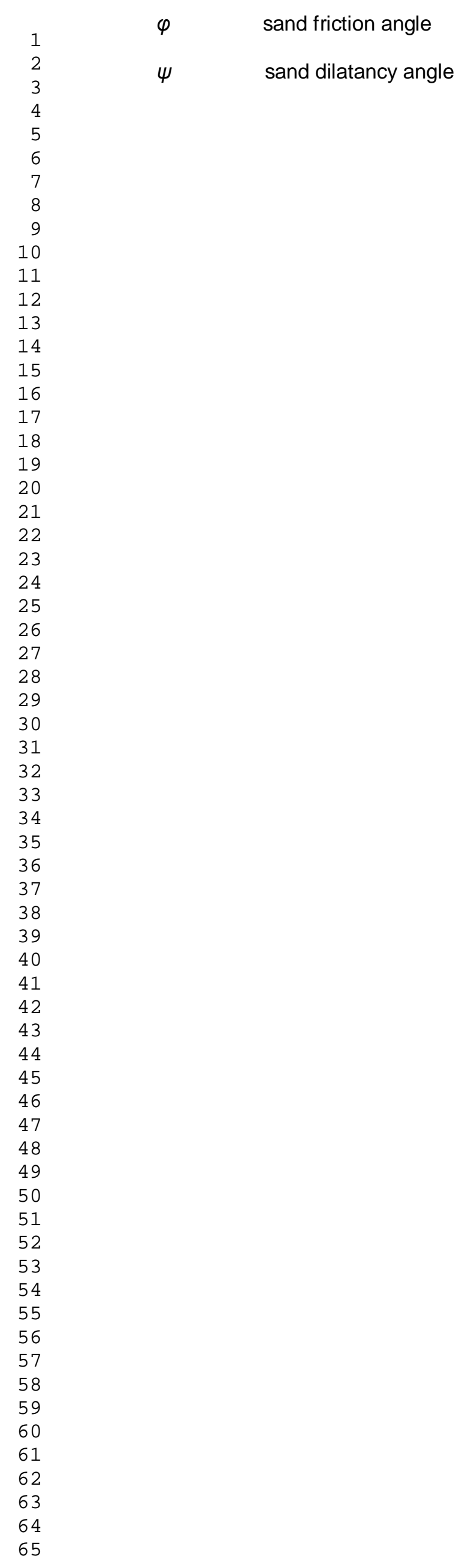


The seismic response of embedded structures is quite distinct from that of above ground structures, as the kinematic loading introduced by the surrounding soils is prevalent, while the inertial loads are often of secondary importance (Kawashima, 2000). In addition, large embedded structures are commonly stiff structures. Hence, during earthquake shaking, strong interaction effects are mobilized between the structure and the surrounding soil, especially for structures of rectangular cross-section. These interaction effects are mainly affected by two crucial parameters, namely: (i) the soil to structure relative flexibility and (ii) the soil-structure interface characteristics. In general, both are changing with the amplitude of seismic excitation as they depend on the soil shear modulus and strength, which are related to the ground strains and the soil non-linear behavior.

Several methods are available in the literature for the evaluation of the response of underground structures and tunnels under seismic shaking (e.g. St. John and Zahrah, 1987; Wang, 1993; Penzien, 2000; Hashash et al., 2001; AFPS/AFTES, 2001; ISO23469, 2005; Anderson et al., 2008; FHWA, 2009). The results of these methods may deviate, even under the same design assumptions, due to both inherent epistemic uncertainties and knowledge shortfall regarding some crucial issues that significantly affect the seismic response (Pitilakis and Tsinidis, 2014). Seismic earth pressures and shear stresses distributions along the perimeter of the embedded structure and complex deformation modes during shaking for rectangular cross sections (e.g. rocking and/or inward deformations) are, among others, issues that are still not entirely understood. 
Along these lines, a series of dynamic centrifuge tests was performed on flexible aluminum square tunnel models embedded in dry sand of different relative density. The soil-tunnel system response was recorded with an extensive instrumentation array comprising of miniature accelerometers, pressure cells and position sensors in addition to strain gauges which recorded the tunnel lining internal forces. The paper describes typical experimental results from a representative test case that is also analyzed by means of a full dynamic time-history numerical analysis of the coupled soil-tunnel system. Simplified constitutive models, commonly used by the engineering practice, are implemented for the description of the sand's dynamic response. Numerical predictions are compared to the experimental data to validate the effectiveness of the numerical modeling. The calibrated numerical models are finally used to validate the accuracy of available simplified design methods used in engineering practice.

\section{Dynamic centrifuge testing}

The experimental program was carried out on the $10 \mathrm{~m}$ diameter Turner beam centrifuge of the University of Cambridge (Schofield, 1980). Three dynamic centrifuge tests were performed on flexible tunnel models embedded in dry sand pluviated to different values of relative density. The tests were performed under a centrifuge acceleration of $50 \mathrm{~g}$ (scale factor $\mathrm{N}=50$ ). Scaling laws are needed to convert the measured quantities from model to prototype scale. Table 1 summarizes the basic scaling laws used herein, derived through dimensional analysis (Schofield, 1981). A large equivalent-shear-beam (ESB) container was used to contain the models (Schofield and Zeng, 1992). In the following we discuss one of the test cases.

The soil deposit was made of uniform Hostun HN31 sand with $90 \%$ relative density. The physical and mechanical properties of the sand are summarized in Table 2. Sand pouring was performed using an automatic hopper system, so as to achieve an almost uniform soil deposit (Madabhushi et al., 2006).

The tunnel model, manufactured using 6063A aluminum alloy, was $100 \mathrm{~mm}$ wide and $220 \mathrm{~mm}$ long, having a lining thickness of $2 \mathrm{~mm}$ (Fig. 1a). The aluminum alloy mechanical properties are summarized in Table 3. According to the scale factor, the model corresponds to a $5 \times 5(\mathrm{~m})$ 
square tunnel having an equivalent concrete lining thickness equal to $0.13 \mathrm{~m}$ (assuming $E_{c}=30$ GPa for the concrete). This thickness is obviously unrealistic in practice, as the design analysis for the static loads will result in a much thicker lining. However, this selection was made in order to study the effect of high flexibility on the tunnel response, but also to obtain clear measurements of the lining strains. To simulate more realistically the soil-structure interface, sand was stuck on the external face of the tunnel-model, creating a rough surface.

Table 1. Centrifuge scaling laws (Schofield, 1981)

\begin{tabular}{|c|c|c|}
\hline Parameter & Model/Prototype & Dimensions \\
\hline Length & $1 / \mathrm{N}$ & $\mathrm{L}$ \\
\hline Mass & $1 / \mathrm{N}^{3}$ & $\mathrm{M}$ \\
\hline Stress & 1 & $\mathrm{ML}^{-1} \mathrm{~T}^{-2}$ \\
\hline Strain & 1 & 1 \\
\hline Force & $1 / \mathrm{N}^{2}$ & $\mathrm{MLT}^{-2}$ \\
\hline Time (dynamic) & $1 / \mathrm{N}$ & $\mathrm{T}$ \\
\hline Frequency & $\mathrm{N}$ & $\mathrm{T}^{-1}$ \\
\hline Acceleration & $\mathrm{N}$ & $\mathrm{LT}^{-2}$ \\
\hline Velocity & 1 & $\mathrm{LT}^{-1}$ \\
\hline
\end{tabular}

Table 2. Hostun HN31 physical and mechanical properties (after Mitrani, 2006)

\begin{tabular}{|c|c|c|c|c|c|c|}
\hline$\rho_{\mathrm{s}}\left(\mathrm{g} / \mathrm{cm}^{3}\right)$ & $e_{\max }$ & $e_{\min }$ & $d_{10}(\mathrm{~mm})$ & $d_{50}(\mathrm{~mm})$ & $d_{60}(\mathrm{~mm})$ & $\varphi_{\mathrm{cv}}\left({ }^{0}\right)$ \\
\hline 2.65 & 1.01 & 0.555 & 0.209 & 0.335 & 0.365 & 33 \\
\hline
\end{tabular}

Table 3. Tunnel-model mechanical properties

\begin{tabular}{|c|c|c|c|}
\hline $\begin{array}{c}\text { Unit weight, } \\
\mathrm{Y}\left(\mathrm{kN} / \mathrm{m}^{3}\right)\end{array}$ & $\begin{array}{c}\text { Young's Modulus, } \\
\mathrm{E}(\mathrm{GPa})\end{array}$ & $\begin{array}{c}\text { Poisson ratio, } \\
\mathrm{v}\end{array}$ & $\begin{array}{c}\text { Tensile strength, } \\
\mathrm{f}_{\mathrm{bk}}(\mathrm{MPa})\end{array}$ \\
\hline 2.7 & 69.5 & 0.33 & 220 \\
\hline
\end{tabular}

A dense monitoring scheme was implemented to monitor the soil-tunnel response (Fig. 2). Miniature piezoelectric accelerometers were used to measure the acceleration in the soil, on the tunnel and on the container. The soil surface settlements were recorded in two locations using linear variable differential transformers (LVDTs), while two position sensors were attached on the upper side of the tunnel walls to capture the vertical displacement and the possible rocking of the tunnel model. Both the LVDTs and the POTs were attached to gantries running above the ESB container. Two miniature total earth pressure cells were attached on the left side wall of 
the tunnel, allowing the measurement of the soil earth pressures on the wall. Resistance strain gauges were attached to the inner and the outer face of the tunnel to measure the lining bending moment and axial force at several locations (Fig. 2). Unfortunately, the bending moment strain gauge at the middle of the roof slab broke during testing. All the instruments were adequately calibrated before and checked after testing. Regarding the strain gauges, a special procedure for their calibration was followed (Tsinidis et al., 2014). The data was recorded at a sampling frequency of $4 \mathrm{~Hz}$ during the swing up and at $4 \mathrm{kHz}$ during shaking.

To estimate the soil shear wave velocity profile air hammer tests were performed (Ghosh and Madabhushi, 2002). A small air-hammer was introduced close to the base of the soil layer while a set of accelerometers were placed above it, forming a vertical array, allowing a record of the arrival times of the waves emanating from the air-hammer. To assure that the arrival times were adequately recorded, the accelerometers along this array were attached on a different acquisition system that allowed for a sampling frequency of $50 \mathrm{kHz}$.

The dynamic input was provided at the container base by a stored angular momentum actuator, which is designed to apply sinusoidal or sine-sweep wavelets (Madabhushi et al., 1998). The model was subjected to a total of eight earthquakes, during two flights; EQ1 to EQ5 were fired during a first flight, while EQ6 to EQ8 were fired during a subsequent flight. Table 4 tabulates the input motion characteristics. As it will be discussed in the following sections, the seismic input motions were not perfectly sinusoidal waves. During each flight, the centrifuge was spun up in steps until $50 \mathrm{~g}$ and then the earthquakes were fired in a row, leaving some time between them to acquire the data.

Table 4. Input motions (bracketed values in prototype scale)

\begin{tabular}{|c|c|c|c|c|c|c|c|c|}
\hline EQ ID & $E Q 1$ & $E Q 2$ & $E Q 3$ & $E Q 4$ & $E^{*} 5^{*}$ & $E^{*} 6^{* *}$ & $E^{*} 7^{* *}$ & $E^{* *}$ \\
\hline $\begin{array}{c}\text { Frequency } \\
\text { f (Hz) }\end{array}$ & $30(0.6)$ & $45(0.9)$ & $50(1)$ & $50(1)$ & $60(1.2)$ & $50(1)$ & $50(1)$ & $50(1)$ \\
\hline $\begin{array}{c}\text { Amplitude } \\
\text { a (g) }\end{array}$ & 1.0 & 4.0 & 6.5 & 12.0 & 12.0 & 5.8 & 6.0 & 11.0 \\
\hline
\end{tabular}

*sine sweep,

${ }^{* *}$ fired during a second flight 
To interpret the experimental results, the data was windowed neglecting the parts of the signals before and after the main shake duration, while a filtering procedure was conducted in the frequency domain. More details about the model construction may be found in Tsinidis et al., 2014.

\section{Numerical analysis}

\subsection{Numerical model}

The test was simulated by means of full dynamic time history analyses, using the finite element code ABAQUS (ABAQUS, 2010). The analyses were performed in prototype scale, assuming plane strain conditions. Fig. 3 presents the numerical model layout.

The soil was meshed with quadratic plane strain elements, while the tunnel was simulated with beam elements. The element size was selected in a way that ensures efficient reproduction of the waveforms of the whole frequency range under study.

The base boundary of the model was simulated as rigid bedrock (shaking table), while for the side boundaries kinematic tie constrains were introduced, forcing the opposite vertical sides to move simultaneously preventing any rotation simulating, in that simplified way, the container.

The soil-tunnel interface was adequately modelled, using a finite sliding hard contact algorithm that is embedded in ABAQUS (ABAQUS, 2010). The model constrains the two media when attached, using the direct constraint enforcement method and Lagrange multipliers (when required), while it also allows separation. The interface friction effect on the soil-tunnel system response was investigated by applying different Coulomb friction coefficients $\mu$, namely $\mu=0$ for the full slip and 0.4 and 0.8 for non-slip conditions. In a final series of analyses, the soil and the tunnel were fully bonded assuming no slip conditions, precluding separation.

The model lining was modeled using an elastic-perfectly plastic material model, with yield strength equal to $220 \mathrm{MPa}$, while the soil response under seismic shaking was simulated in two ways. In a first series of analyses, a visco-elastic model was implemented, introducing a 
degraded shear modulus and viscous damping (e.g. following the equivalent linear approximation method), in order to check the effectiveness of this commonly used method to describe several aspects of the recorded response. To account for the soil permanent deformations, in a second series of analyses, a non-associated elasto-plastic Mohr-Coulomb model was used, assuming the same elastic properties for the sand (e.g. degraded stiffness) as in the visco-elastic analyses.

The input motion was introduced at the model base in terms of acceleration time histories, referring to the motion recorded by the reference accelerometer (A1, Fig. 2). The analyses were performed in two steps; first the gravity loads were introduced, while in a second step the earthquake motions were applied in a row, replicating each test flight. To this end, the loading history for the sand was adequately simulated.

\subsection{Sand stiffness and strength}

The sand small strain shear modulus $\left(G_{\max }\right)$ was described according to Hardin and Drenvich (1972), which fits reasonably well with the air hammer test results and also results of laboratory tests (resonant column) that were performed on the specific sand fraction (Pistolas et al., 2014). Fig. 4 compares the estimated small strain shear wave velocity gradient from different methods and the distribution proposed according to Hardin and Drenvich (1972).

For the estimation of the sand real stiffness and viscous damping during shaking a trial and error procedure was applied. More specifically, 1D equivalent linear (EQL) soil response analyses of the soil deposit were performed, using different sets of $G-\gamma-D$ curves for cohesionless soils (e.g. Seed et al., 1986, Ishibashi and Zhang, 1993). The analyses were performed in the frequency domain using EERA (Bardet et al., 2000). The computed horizontal acceleration time histories and amplification were compared to the recorded data of the free field array (sensors A4 to A8 in Fig. 2). The finally adopted G- $y-D$ curves were those that resulted in the best fitting of the numerical predictions with the experimental results (Ishibashi and Zhang, 1993 for small confining pressure). Comparison of the numerical G- $\gamma$-D curves with empirical ones (Seed et al., 1986) and laboratory results from resonant column and cyclic 
triaxial tests for the specific sand fraction (Pistolas et al., 2014) are provided in Fig. 5. The adopted numerical curves compare reasonably well with the laboratory test results over a wide range of strain amplitudes.

1D equivalent linear soil response analyses for the finally selected $G_{\max }$ and $G-\gamma-D$ curves revealed that a redacted distribution according to Hardin and Drnevich adequately reproduced the degraded sand shear modulus during shaking. To this end, the following expression was used for the description of the degraded strain shear modulus:

$$
G=\alpha \times 100 \frac{(3-e)^{2}}{1+e}\left(\sigma^{\prime}\right)^{0.5}
$$

1.

where: $e$ is the void ratio, $\sigma^{\prime}$ is the mean effective stress (in MPa), $G$ is the degraded shear modulus (in $\mathrm{MPa}$ ) and $\alpha$ is the mean reduction value for all the shakes during each flight, ranging between $0.3-0.4$ for the different flights studied. Earth coefficient at rest $\left(K_{o}\right)$ was computed as (Jaky, 1948):

$K_{o}=1-\sin \varphi$

2.

where $\varphi$ is the sand friction angle.

The reduced values for the sand shear modulus come in accordance with the shear moduli computed from the stress-strain loops, estimated using the recorded acceleration time histories across the free field array (A4-A8 in Fig.2) according to Zeghal and Elgamal (1994). It is noteworthy that this high decrease of the soil stiffness and increase of damping in this type of test is also reported by other researchers (Kirtas et al., 2009; Pitilakis and Clouteau, 2010; Lanzano et al., 2010; Conti et al., 2013; Li et al., 2013).

In the final 2D full dynamic analysis, the degraded elastic stiffness of the sand material was introduced through a FORTRAN user-subroutine, which correlates the stiffness with the 
confining pressure at each soil element integration point. To this end, the effect of the tunnel existence on the surrounding sand stiffness was explicitly accounted for.

Viscous damping (7-15\%) estimated from the soil response analyses results was employed in the numerical analysis in the form of the frequency dependent Rayleigh type. For the elastoplastic analyses additional energy dissipation was introduced by the hysteretic soil response.

Regarding the sand strength parameters; a friction angle $\varphi$ equal to $33^{\circ}$ (critical friction angle for the specific sand fraction) was used, while the dilatancy angle $\psi$ was assumed equal to $3^{\circ}$. A sensibility analysis on the effect of the friction and dilatancy angles to the numerical response revealed that higher values of $\varphi$ and $\psi$ resulted in minor differences to the computed response, affecting slightly the permanent soil response near the tunnel.

\section{Numerical predictions versus experimental results}

Representative comparisons between the recorded and the computed response are presented in this section. Through the presentation of relevant data, several crucial aspects of the soiltunnel response are discussed. Results are generally shown at model scale, if not differently stated, while the notation refers to Fig. 2.

\subsection{Horizontal acceleration}

Fig. 6 presents time windows of typical comparisons between the recorded and the computed acceleration time histories at two representative locations (middle section of left side-wall, A13; top receiver of tunnel accelerometer array, A10). In Fig. 7 representative comparisons between the computed and recorded horizontal acceleration amplification along the free-field and the tunnel vertical accelerometer arrays are depicted. Generally, both visco-elastic and elastoplastic analyses reveal similar responses and amplification, while numerical predictions are in good agreement with the records both in terms of amplitude and frequency content (Fig. 8). The differences, generally minor, are mainly attributed to the inevitable differences between the assumed soil mechanical properties (stiffness and damping) and their actual values during the test. The larger deviation observed at the tunnel roof slab is probably attributed to a problematic 
record at this location. Actually, the slab inward deformations, discussed in the following section, are likely to have caused a malfunction of the accelerometer at this location. It is noteworthy to mention the higher frequencies of the signals observed in the Fourier spectra shown in Fig. 8. Significantly more energy content is associated with higher frequencies than with the predominant one. These higher frequencies that are attributed to the experimental equipment mechanical response (Brennan et al., 2005) are described quite efficiently, by the numerical model.

\subsection{Tunnel deformed shapes}

Fig. 9 presents time-windows of typical comparisons between the recorded and computed vertical accelerations at the sides of the tunnel roof slab. Experimental results are slightly larger than the numerical predictions. The difference is probably attributed to the parasitic yawing movement of the whole model on the shaking table during shaking that may amplify vertical acceleration and cannot be reproduced by the numerical analysis. The no-slip condition analyses results are closer to the recorded response. Generally, signals are out of phase indicating a rocking mode of vibration for the tunnel, in addition to the classical racking mode. Fig. 10 presents typical computed deformed shapes of the tunnel during shaking, verifying this complex racking-rocking response. Due to the high flexibility of the tunnel, inward deformations are also observed, for the slabs and the walls.

\subsection{Dynamic earth pressures}

Typical comparisons between the computed and recorded dynamic earth pressures time histories at the left side-wall are presented in Fig. 11. The effect of the soil-tunnel interface characteristics on the computed earth pressures is also highlighted. Residual values are reported after shaking, as a result of the soil yielding and densification around the tunnel. This post-earthquake residual response has been also reported during similar centrifuge tests (Cilingir and Madabhushi, 2011a; 2011b) and is amplified with the flexibility of the tunnel. Pressure dynamic increments are found to be larger near the stiff corners of the tunnel. Generally, numerical predictions for no-slip conditions are closer to the recorded response. Observed differences can be mainly attributed to discrepancies between the assumed and the 
actual in test mechanical properties of the sand and the soil-tunnel interface and also to recording issues that are related with the response of the miniature earth pressures cells in the case of granular dry sands. Accurate measurement of earth pressures in sands with miniature pressure cells is quite difficult, as the relative stiffness of the sensing plate may affect the readings, while there are problems related to the grain size effect (Cilingir, 2009). Moreover, inward deformations of the tunnel wall may slightly change the recording direction (small inclination of the pressure cell) and therefore the recorded earth pressure may be different from the "normal" value computed by the analysis. Considering the aforementioned, comparisons indicate a reasonably good agreement.

Fig. 12 presents typical dynamic earth pressure distributions around the tunnel perimeter referring to the time step of the tunnel maximum racking distortion. Soil yielding around the tunnel results in stress redistributions, leading to a different response between elasto-plastic and visco-elastic analyses. Moreover, soil-tunnel interface properties seem to affect the soil yielding response in the area adjacent to the tunnel (Fig. 13) and therefore the pressure distributions. This relation between the soil yielding response and the soil-tunnel interface properties is also reported by Huo et al., 2005.

\subsection{Soil dynamic shear stresses}

Fig. 14 presents representative soil dynamic shear stress distributions around the tunnel computed for the time step of maximum racking distortion. As for the earth pressures, soil yielding affects the shear stress around the tunnel. Generally, shear stresses tend to increase near the tunnel corners due to the higher earth pressures (confining pressures for the tunnel) at these locations. As expected, interface friction plays an important role on the shear stresses distributions and magnitudes. Actually, an increase of the soil-tunnel interface friction results in an increase of the shear stresses along the middle sections of the tunnel slabs and walls.

\subsection{Lining dynamic bending moment}

Representative comparisons between recorded and computed dynamic bending moment time histories are presented in Fig. 15. The observed differences are again attributed to the 


\subsection{Lining dynamic axial force}

Similar to the dynamic bending moments, residual values were recorded for the lining axial forces (Fig. 17). These residuals were generally smaller than the bending moment ones and were found to be larger along the slabs. In addition, dynamic axial forces recorded on the sidewalls were out of phase, verifying the racking-rocking response of the tunnel during shaking (Tsinidis et al., 2014). Numerical results revealed similar tendencies. The effect of the mobilized friction (along the interface), on the lining axial forces is quite important (Fig. 17). Similar to the dynamic earth pressures, recorded axial forces were found to be in better agreement with the numerical predictions assuming no-slip conditions. This observation may be attributed to the inward deformations of the model-tunnel that are amplified by the tunnel's high flexibility. The surrounding sand is actually squeezing the tunnel, leading to a more rigid soil-tunnel interface (no separation-no slip conditions).

It is noteworthy that both visco-elastic and elasto-plastic analyses reproduce the recorded dynamic internal forces increments reasonably well (Fig. 18). These increments, which are computed as the semi-amplitude of the maximum values of the loading cycles in the internal forces time histories are in both cases amplified near the tunnel corners. 


\section{Simplified analysis methods}

Simplified methods are commonly used in design practice, especially during preliminary stages of design, mainly due to their simplicity and reduced computational cost compared to the nonlinear full dynamic analysis. The majority of these methods rely on the assumption that the seismic load is introduced on the tunnel in a quasi-static manner, and therefore they do not account for the dynamic soil-structure interaction effects (Pitilakis and Tsinidis 2014). In this section two of the most commonly used methods are discussed, namely, the design procedure proposed by Wang (1993) and the pseudo-static seismic coefficient deformation method (FHWA, 2009) or detailed equivalent static analysis method (ISO 23469, 2005).

According to the first methodology, the tunnel seismic response is evaluated through a simple static frame analysis. The structural racking distortion due to ground shaking is modelled as an equivalent static load or pressure that is imposed on the frame (Fig. 19a). This "structural" racking distortion is evaluated by the free field ground racking distortion that is properly adjusted, through the so called racking ratio (structural to ground racking distortions), in order to account for the soil-tunnel interaction effects. Racking ratio is correlated with the soil to tunnel relative flexibility that is expressed through the flexibility ratio $F$. According to NCHPR611 regulations (Anderson et al., 2008) racking ratio can be computed as:

$R=\frac{\Delta_{s t r}}{\Delta_{f f}}=\frac{2 F}{(1+F)}$

3.

In the detailed equivalent static analysis method, a 2D soil-tunnel numerical model is proposed for the analysis, similar to the dynamic analysis (ISO 23469, 2005; FHWA, 2009). The seismic load is introduced in a pseudo-static manner, as equivalent inertial load throughout the entire model that corresponds to the ground free-field acceleration amplification profile (Fig. 19b). In an alternative of this method, equivalent seismic load is introduced as a ground deformation pattern on the numerical model boundaries (Fig. 19c), corresponding to the free field ground response (Kontoe et al., 2008; Hashash et al., 2010). 
The test case presented herein is used as a case study to verify the effectiveness of the aforementioned simplified methods. More specifically, the results of the implemented simplified methods are compared to the calibrated dynamic analysis that is used as the benchmark case. The comparisons are made in terms of computed racking ratio and dynamic bending moment in the lining which are considered to be representative parameters for the validation. The flexibility ratio for the given case is estimated to be equal to $F=62.5$ indicating a quite flexible structure compared to the surrounding soil. To further extend the comparisons, a second series of analyses are performed increasing the tunnel lining thickness, so as to model a rigid tunnel $(F=$ 0.29). Both static and dynamic analyses are performed separately for each earthquake scenario, using the numerical model presented in Fig. 3. Although, simplified methods propose an equivalent linear approximation (e.g. degraded shear modulus computed from site response analysis) to account for the soil non-linear response under ground shaking (e.g. Hashash et al., 2010), both elastic and elasto-plastic analyses are performed, using the constitutive models presented before, in order to check the effect of the soil permanent deformations on the results. Moreover, to study the effect of the soil-tunnel interface properties, the analyses are carried out under full slip and no slip conditions. Sand mechanical properties (e.g. stiffness and strength) are selected in order to correspond to that of the dynamic analysis, while the equivalent seismic loads (e.g. inertia forces or ground displacements) are computed from the dynamic analysis, referring to the free field and for the time step of maximum tunnel racking distortion. To investigate the effect of the input motion amplitude, the analyses are performed for EQ3 $(0.13 \mathrm{~g})$ and for EQ4 (0.24 g) according to Table 4, while to study the input motion frequency content on the response, a final set of analyses are performed using the JMA record from the 1995 Kobe earthquake that is scaled down to $0.24 \mathrm{~g}$. The following presented results refer to extreme scenarios regarding the tunnel flexibility and therefore they should be interpreted as limit cases. Soil strength parameters may affect the soil permanent response and therefore may alter the results of non-linear analyses. Considering the relatively low strength estimated in the examined cases and the associated increased yielding response, the results may be considered conservative. 
Table 5 compares the racking ratios estimated from different approaches for EQ4, assuming elastic soil response. Generally, numerical results for no-slip conditions resulted in slighlty larger racking ratios. Moreover, racking ratios computed from the equivalent static analyses seem to be slightly lower compared to the dynamic analysis results. The NCHPR611 analytical relation (Anderson et al., 2008) overestimates the racking ratio for the flexible tunnel, while for the rigid tunnel, and assuming no-slip conditions, numerical analyses result in a ratio larger than the analytical estimation. An underestimation of the racking ratio will result in underestimation of the lining forces. On the contrary, an overestimation of the racking ratio may lead to an overdesign that may be considered as a conservative "safe" design concept. However an overdesign is not only needlessly expensive but may lead to the stiffening of the structure that may in turn change the whole response pattern in a detrimental way.

Table 5. Racking ratios estimated by different methods under the assumption of elastic soil response for EQ4.

\begin{tabular}{|c|c|c|c|c|}
\hline Racking ratio & $\begin{array}{c}\text { Dynamic } \\
\text { analysis }\end{array}$ & $\begin{array}{c}\text { Equivalent } \\
\text { static analysis - } \\
\text { Force }\end{array}$ & $\begin{array}{c}\text { Equivalent } \\
\text { static analysis - } \\
\text { Displacement }\end{array}$ & $\begin{array}{c}\text { NCHPR611 } \\
\text { Anderson et al. } \\
(2008) \\
(\mathrm{R}=2 \mathrm{~F} /(1+\mathrm{F}))\end{array}$ \\
\hline Flexible tunnel - full slip & 1.3 & 1.27 & 1.22 & 1.96 \\
\hline Flexible tunnel - no slip & 1.46 & 1.42 & 1.40 & 1.96 \\
\hline Rigid tunnel - full slip & 0.5 & 0.47 & 0.40 & 0.45 \\
\hline Rigid tunnel - no slip & 0.74 & 0.72 & 0.65 & 0.45 \\
\hline
\end{tabular}

Fig. 20 presents representative comparisons of the dynamic bending moment distributions along the tunnels perimeter, computed with different design methods. Elasto-plastic analyses numerical results for the flexible tunnel case are also compared with the experimental data (Fig. 20b). Assuming elastic soil response, equivalent static analyses are generally reproducing well the computed bending moment distribution from the dynamic analysis. However, the maximum bending moment is underestimated, for both the flexible and the rigid tunnel, especially when the equivalent seismic load is introduced in terms of deformation at the model boundaries.

Accounting for the soil permanent deformations (elasto-plastic analyses), bending moment distributions become more complex, especially in the flexible tunnel case, due to the associated larger soil yielding. Experimental data is generally closer to the dynamic analysis results (Fig 
Table 6. Comparisons between recorded and computed from different design methods, bending moments at receivers positions (EQ3 elasto-plastic analyses for full slip conditions)

\begin{tabular}{|c|c|c|c|c|}
\hline & \multicolumn{4}{|c|}{$\mathrm{M}(\mathrm{Nmm} / \mathrm{mm})$} \\
\hline Position & $\begin{array}{c}\text { Full dynamic } \\
\text { analysis }\end{array}$ & $\begin{array}{c}\text { Equivalent static } \\
\text { analysis - Force }\end{array}$ & $\begin{array}{c}\text { Equivalent static } \\
\text { analysis - Deformation }\end{array}$ & Test \\
\hline SG-B1 & -3.90 & -2.55 & -1.74 & -4.16 \\
\hline SG-B2 & -1.59 & -0.25 & -0.20 & -3.59 \\
\hline SG-B4 & -4.00 & -1.10 & -0.25 & -4.21 \\
\hline
\end{tabular}

Fig. 21 plots static to dynamic bending moment ratios that are computed at a crucial lining section (Joint C, Fig. 20) under different assumptions regarding the soil-tunnel interface properties, the soil response (elastic and elasto-plastic analyses) and the input motion characteristics. Generally, equivalent static analyses underestimate the bending moment compared to the full dynamic analysis. For the elastic analyses, the differences may reach 20 to $30 \%$. The discrepancies are even higher for the elasto-plastic analyses (differences up to 60 $\%)$, especially for the flexible tunnel case. The differences are generally higher for the cases where the equivalent seismic load is introduced in terms of ground displacements at the model boundaries. This may be attributed to the relatively large distance between the tunnel and the numerical model boundaries ( $14.3 \mathrm{~m}$ for the side boundaries), where the ground deformation is imposed. By increasing this distance it is possible that a greater amount of induced ground strain is artificially absorbed by the soil elements, thus "relieving" the structure and altering the 
Similar conclusions are generally drawn for other parameters of the soil-tunnel response (e.g. lining axial forces and dynamic earth pressures around the tunnel).

\section{Conclusions}

The paper presents and discusses representative experimental results from a series of dynamic centrifuge tests on a flexible tunnel model embedded in dry sand, along with results from numerical simulations of the tests. Numerical models were found capable of reproducing the recorded response with reasonable engineering accuracy. Some inevitable differences between the recorded and the computed response are mainly attributed to the differences between the estimated soil, tunnel and soil-tunnel interface mechanical properties, compared to the real test values that are difficult to know precisely, and also to the inevitable simplification of the implemented constitutive models.

Both the experimental and the numerical data revealed a rocking mode of vibration in addition to the racking distortion. Inward deformations were also observed due to the high flexibility of the tunnel. Post earthquake residual values were recorded and computed for the earth pressures on the side-walls and the lining forces, which were amplified with the increasing flexibility of the tunnel. This complex response associated with residual deformations and internal forces in the lining cannot be reproduced by the equivalent linear approximation method that is often proposed in regulations and used in engineering practice. Therefore, this approach should be used with caution, especially when the tunnel is quite flexible and high soil nonlinearity is expected as in the case of strong earthquakes. 
The calibrated dynamic numerical models were finally used as benchmark to validate the accuracy of currently used simplified methods. Racking ratios computed from the equivalent static analyses found to be slightly lower compared to the dynamic analysis results, while the NCHPR611 analytical relation (Anderson et al., 2008) was found to overestimate the racking ratio for the flexible tunnel case. In general, it has been found that simplified methods underestimated the tunnel lining forces compared to the full dynamic analysis. Assuming an elastic soil response the differences were up to $20 \%$, while the discrepancies were much higher for the cases when the soil permanent deformation was accounted for. Equivalent static analyses, where the load is introduced in terms of distributed inertial loads throughout the model, were found more efficient. The main conclusion drawn is that simplified methods should be used with caution, mainly during preliminary stages of design, and for cases where high soil non-linearity is not expected (e.g. rather low to medium seismic intensities).

\section{Acknowledgements}

The research leading to the presented experimental results has received funding from the European Community's Seventh Framework Programme [FP7/2007-2013] for access to the Turner Beam Centrifuge, Cambridge, UK, under grant agreement $n^{\circ} 227887$ [SERIES - Seismic Engineering Research Infrastructures for European Synergies, http://www.series.upatras.gr/]. The excellent technical support received by the Technicians of Schofield Centre is gratefully acknowledged.

\section{References}

ABAQUS (2010) ABAQUS: theory and analysis user's manual version 6.10. Providence, RI, USA: Dassault Systèmes SIMULIA Corp.

AFPS/AFTES (2001) Guidelines on earthquake design and protection of underground structures. Working group of the French association for seismic engineering (AFPS) and French tunnelling association (AFTES) Version 1, France.

Anderson DG, Martin, GR, Lam I and Wang JN (2008) NCHPR611: Seismic analysis and design of retaining walls, buried structures, slopes and embankments. National Cooperative Highway Research Program, Transportation Research Boards, Washington, DC, USA. 
Bardet JB, Ichii $\mathrm{K}$ and Lin $\mathrm{CH}$ (2000) EERA: a computer program for equivalent-linear earthquake site response analyses of layered soil deposits. University of Southern California, Department of Civil Engineering, Los Angeles, USA.

Brennan AJ, Thusyanthan NI, Madabhushi SPG (2005) Evaluation of shear modulus and damping in dynamic centrifuge tests. J Geotech Geoenviron Eng 131(12):1488-1497.

Cilingir U (2009) Seismic response of tunnels. PhD Thesis, University of Cambridge, UK.

Cilingir U and Madabhushi SPG (2011a) A model study on the effects of input motion on the seismic behaviour of tunnels. Soil Dyn Earthq Eng 31:452-462.

Cilingir U and Madabhushi SPG (2011b) Effect of depth on the seismic response of square tunnels. Soils Found 51(3):449-457.

Conti R, Viggiani G and Perugini F (2013) Numerical modelling of centrifuge dynamic tests of circular tunnels in dry sand. Acta Geotech. doi: 10.1007/s11440-013-0286-8.

Dowding $\mathrm{CH}$ and Rozen A (1978) Damage to rock tunnels from earthquake shaking. $J$ Geotech Eng Div 104:175-191.

FHWA (Federal Highway Administration) (2009) Technical manual for design and construction of road tunnels - Civil elements. U.S. Department of transportation. Federal Highway Administration. Publication No. FHWA-NHI-09-010. Washington D.C., USA.

Ghosh B and Madabhushi SPG (2002) An efficient tool for measuring shear wave velocity in the centrifuge. In Proceedings of International Conference on Physical Modelling in Geotechnics (Phillips R, Guo PJ, Popescu R(eds.)), St Johns, NF, Canada. AA Balkema publishers 119_ 124.

Hardin BO and Drnevich VP (1972) Shear modulus and damping in soils: design equations and curves. J Soil Mech Foundations 98: 667-692.

Hashash YMA, Hook JJ, Schmidt B, Yao JI-C (2001) Seismic design and analysis of underground structures. Tunnelling Undergr Space Technol 16(2): 247-293.

Hashash YMA, Karina K, Koutsoftas D and O'Riordan N (2010) Seismic design considerations for underground box structures. In Proceedings of Earth Retention Conference - Earth Retention Conference 3, Bellevue, WA, United states, ASCE, 620-637. 
Huo H, Bodet A, Fernández G and Ramirez J (2005) Load transfer mechanisms between underground structure and surrounding ground: evaluation of the failure of the Daikai station. J Geotech Geoenviron 131(12):1522-1533.

lida H, Hiroto T, Yoshida N, Iwafuji M (1996) Damage to Daikai subway station. Soils Found, Special Issue on Geotechnical Aspects of the January 17 1995, Hyogoken-Nambu Earthquake. Japanese Geotechnical Society, Japan, pp 283-300.

Ishibashi I and Zhang XJ (1993) Unified dynamic shear moduli and damping ratios of sand and clay. Soils Found 33:182-191.

ISO 23469 (2005) Bases for design of structures - Seismic actions for designing geotechnical works. International Standard ISO TC 98 / SC3 / WG10.

Jaky J (1948) The coefficient of earth pressure at rest. J Union Hung Eng Arch 78(22):355-358.

Kawashima K (2000) Seismic design of underground structures in soft ground: a review. In Geotechnical aspects of underground construction in soft ground (Kusakabe, Fujita, Miyazaki (eds.)). Balkema, Rotterdam.

Kirtas E, Rovithis E and Pitilakis K (2009) Subsoil Interventions Effect on Structural Seismic Response. Part I: Validation of Numerical Simulations. J Earthquake Eng 13:155-169.

Kontoe S, Zdravkovic L, Potts D and Mentiki C (2008) Case study on seismic tunnel response. Can Geotech J 45:1743-1764.

Li Z, Escoffier S and Kotronis P (2013) Using centrifuge tests data to identify the dynamic soil properties: Application to Fontainebleau sand. Soil Dyn Earthquake Eng 52:77-87.

Madabhushi SPG, Schofield AN and Lesley S (1998) A new stored angular momentum (SAM) based actuator. In Proceedings of the international conference Centrifuge 98 (Kimura T, Kusakabe O, Takemura J (eds.)) Tokyo, Japan. AA Balkema publishers, pp 111-116.

Madabhushi SPG, Houghton NE, Haigh SK (2006) A new automatic sand pourer for model preparation at University of Cambridge. In Proceedings of 6th international conference on physical modelling in geotechnics, Hong Kong.

Lanzano G, Bilotta E, Russo G, Silvestri F, Madabhushi SPG (2010) Dynamic centrifuge tests on shallow tunnel models in dry sand. In Proceedings of the VII international conference on physical modelling in geotechnics (ICPMG 2010). Taylor \& Francis, Zurich, pp 561-567. 
Mitrani H (2006) Liquefaction Remediation Techniques for Existing Buildings. PhD Thesis, University of Cambridge, UK.

Owen GN and Scholl RE (1981) Earthquake engineering of large underground structures. Report No. FHWA/RD-80/195, Federal Highway Administration and National Science Foundation, USA.

Penzien J (2000) Seismically induced racking of tunnel linings. Earthquake Eng Struct Dyn 29:683-691.

Pistolas GA, Tsinaris A, Anastasiadis A and Pitilakis K (2014) Undrained dynamic properties of Hostun sand. In Proceedings of 7th Greek Geotechnics Conference. Athens, Greece (in Greek)

Pitilakis D and Clouteau D (2010) Equivalent linear substructure approximation of soilfoundation-structure interaction: model presentation and validation. Bull Earthquake Eng 8:257-282.

Pitilakis K and Tsinidis G (2014) Performance and Seismic Design of Underground Structures. In Earthquake Geotechnical Engineering Design. (Maugeri M and Soccodato C (eds.)). Geotechnical Geological and Earthquake Engineering, 28, Springer International Publishing, Switzerland, pp.279-340.

Schofield AN (1980) Cambridge Geotechnical Centrifuge Operations. Geotechnique 30(3): $227-$ 268.

Schofield AN (1981) Dynamic and earthquake centrifuge modelling. In Proceedings of International Conference in Advances in Geotechnical Earthquake Engineering and Soil Dynamics, Rolla, USA.

Schofield AN and Zeng X (1992) Design and performance of an equivalent shear beam (ESB) container for earthquake centrifuge modelling. Technical Report, CUED/D-Soils/l'R245, Cambridge University, UK.

Seed HB, Wong RT, Idriss IM and Tokimatsu K. (1986) Moduli and damping factors for dynamic analyses of cohesionless soils. J Geotech Eng Division ASCE 112(11):1017-1032.

Sharma S and Judd WR (1991) Underground opening damage from earthquakes. Eng Geol 30:263-276 
St. John CM and Zahrah TF (1987) Aseismic design of underground structures. Tunn Undergr Space Technol 2(2):165-197

Tsinidis G, Heron C, Pitilakis K and Madabhushi SPG (2014) Physical modeling for the evaluation of the seismic behavior of square tunnels. In Seismic evaluation and rehabilitation of structures. (Ilki A and Fardis M (eds.)). Geotechnical Geological and Earthquake Engineering, 26, Springer International Publishing, Switzerland, 2014, pp.389-406.

Wang JN (1993) Seismic design of tunnels: a simple state of the art design approach. Parsons Brinckerhoff, New York.

Wang WL, Wang TT, Su JJ, Lin CH, Seng CR and Huang TH (2001) Assessment of damage in mountain tunnels due to the Taiwan Chi-Chi earthquake. Tunn Undergr Space Technol 16:133-150.

Zeghal M and Elgamal AW (1994) Analysis of Site Liquefaction Using Earthquake Records. J Geotech Eng ASCE 120:996-1017.

\section{Figure captions}

Figure 1. (a) Tunnel-model, (b) tunnel placement in the model, (c) completed model in the equivalent shear beam container.

Figure 2. Model layout and instrumentation scheme.

Figure 3. Numerical model in ABAQUS.

Figure 4. Small strain shear wave velocity profiles estimated from air hammer tests $(A H)$ and resonant column tests $(\mathrm{RC})$ compared to the Hardin and Drenvich (1972) empirical formulation.

Figure 5. Adopted G-Y-D curves compared to resonant column (RC) and cyclic triaxial test results (TX) (Pistolas et al., 2014) and empirical proposals (Seed et al., 1986).

Figure 6. Time windows of comparisons between recorded and computed horizontal acceleration time histories for different seismic shaking intensities.

Figure 7. Horizontal acceleration amplification along the free field and the tunnel accelerometer vertical arrays for different seismic shaking intensities.

Figure 8. Typical Fourier spectra of computed and recorded acceleration time histories. 
Figure 9. Time windows of recorded and computed vertical acceleration time histories at the sides of the tunnel roof slab for EQ4 earthquake.

Figure 10. Tunnel deformed shapes for time steps of maximum tunnel racking distortion computed by the numerical analyses; EQ4 earthquake, no slip conditions (deformations scale $\times 60)$.

Figure 11. Recorded and computed dynamic earth pressures time histories on the left side wall for different seismic intensities; effect of the soil-tunnel interface characteristics.

Figure 12. Dynamic earth pressures distributions along the perimeter of the tunnel for the time step of maximum racking distortion; effect of the soil-tunnel interface characteristics and soil permanent response.

Figure 13. Soil plastic deformations computed by the numerical analyses around the tunnel at the end of the first flight (deformations scale $\times 10$ ).

Figure 14. Soil dynamic shear stress distributions around the tunnel at the time step of maximum racking distortion; effect of the soil-tunnel interface properties.

Figure 15. Recorded and computed dynamic bending moment time histories for different time intensities; effect of the soil-tunnel interface properties.

Figure 16. Dynamic bending moment distributions along the tunnel perimeter for EQ4 assuming no slip conditions (a) time step of maximum racking distortion, (b) residual values at the end of shaking.

Figure 17. Recorded and computed axial force time histories at the left side wall and the roof slab; effect of the soil-tunnel interface properties.

Figure 18. Internal forces dynamic increments along the tunnel perimeter (a) bending moment for EQ3, (b) axial force for EQ4.

Figure 19. Schematic representation of the simplified analysis methods, (a) Wang (1993) simplified method, (b) detailed equivalent static analysis method-distributed inertial loads, (c) detailed equivalent static analysis method-imposed deformations at model boundaries.

Figure 20. Dynamic bending moment distributions along the tunnel perimeter computed from different methods for EQ3; (a) flexible tunnel-elastic analysis, (b) flexible tunnel-elasto-plastic analysis, (c) rigid tunnel-elastic analysis, (d) rigid tunnel-elasto-plastic analysis. 
Figure 21. Static to dynamic bending moment ratios; (a) flexible tunnel-elastic analysis, (b) flexible tunnel-elasto-plastic analysis, (c) rigid tunnel-elastic analysis, (d) rigid tunnel-elastoplastic analysis. 


\section{Fig01}

Click here to download Figure: Tsinidisfig01.eps
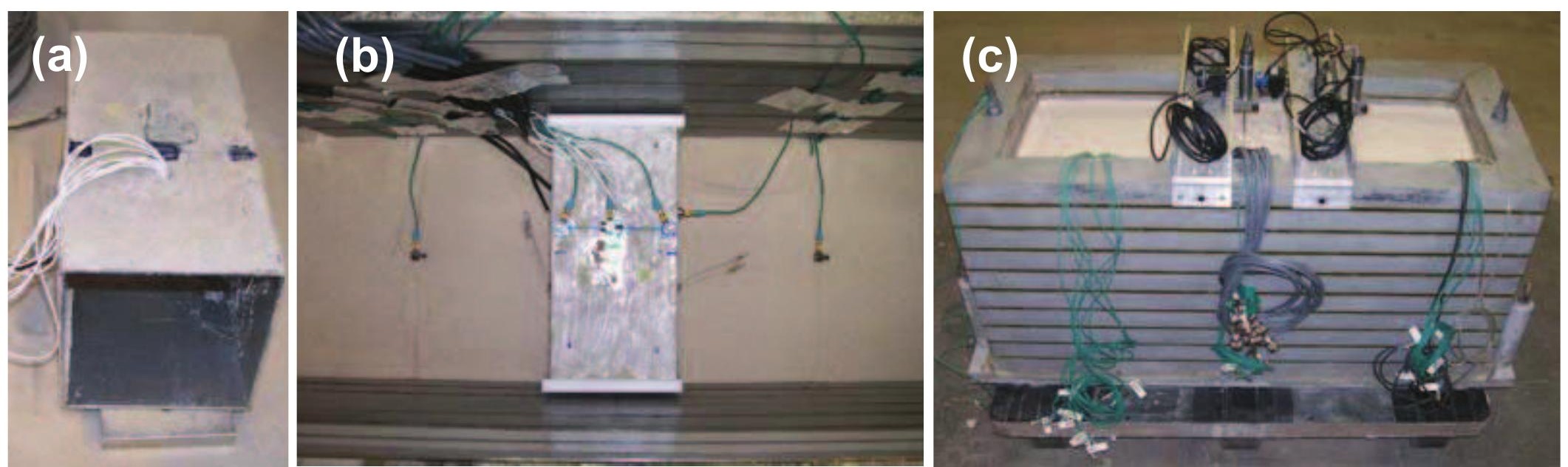


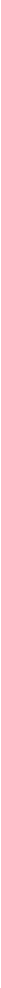

$\downarrow$ Accelerometer $\bullet$ Pressure cell $\perp$ LVDT POT Strain gauge 


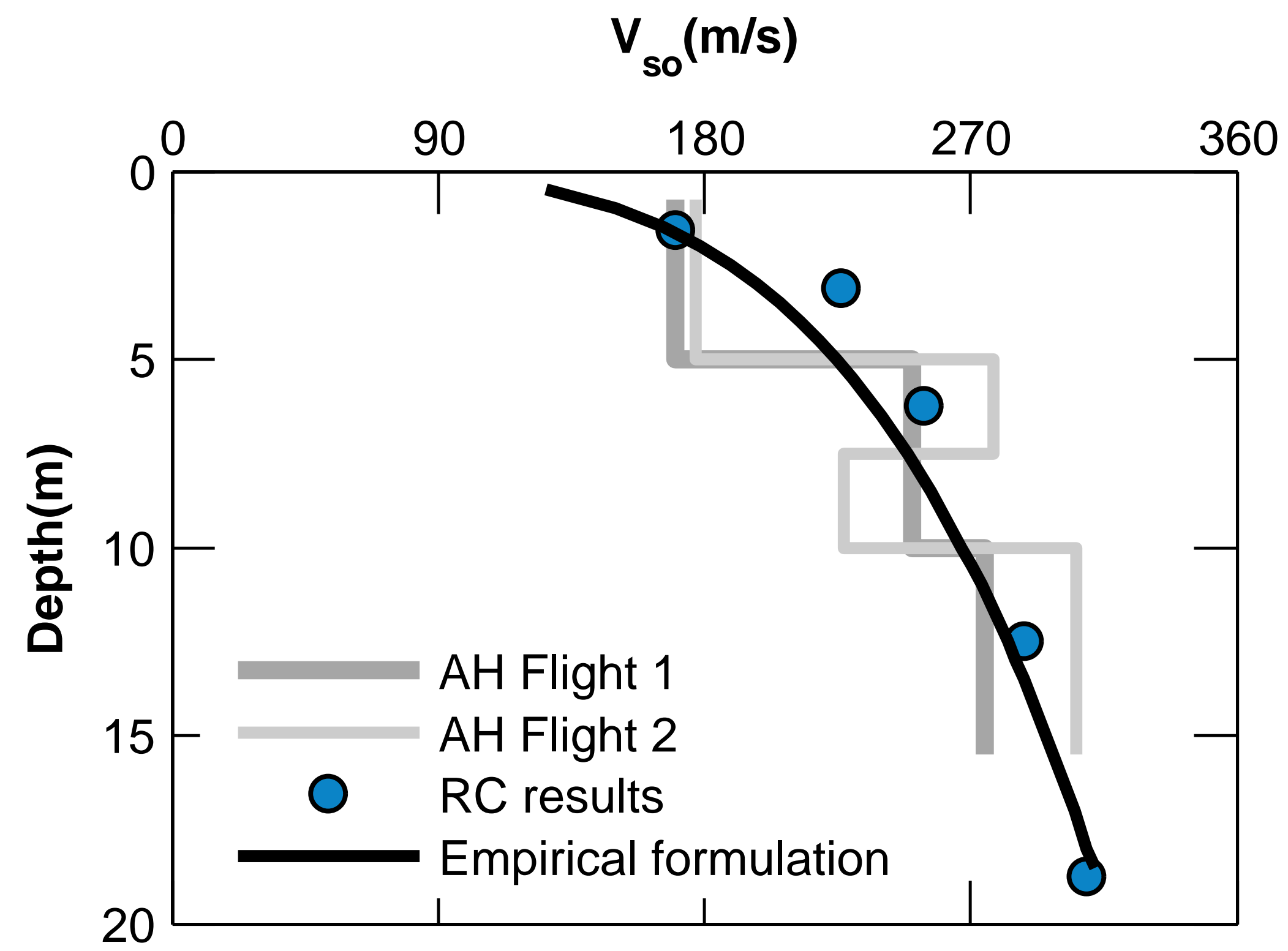



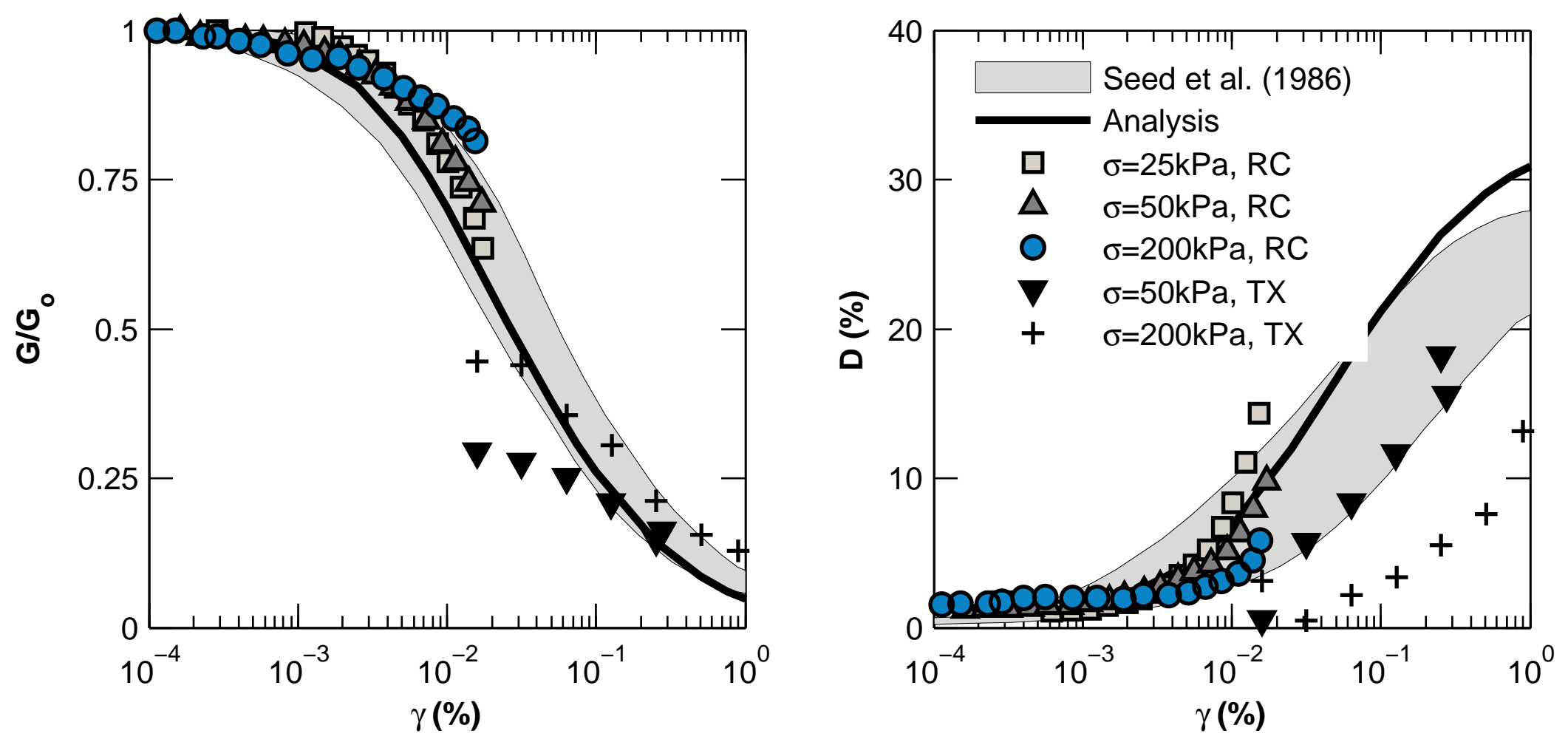


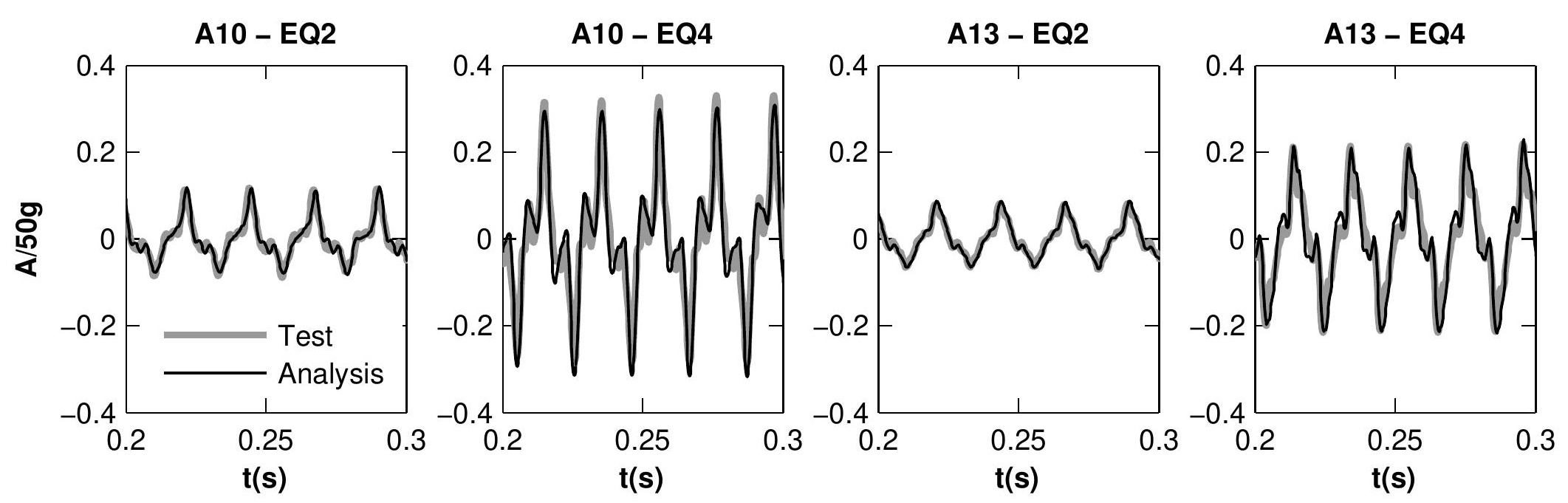




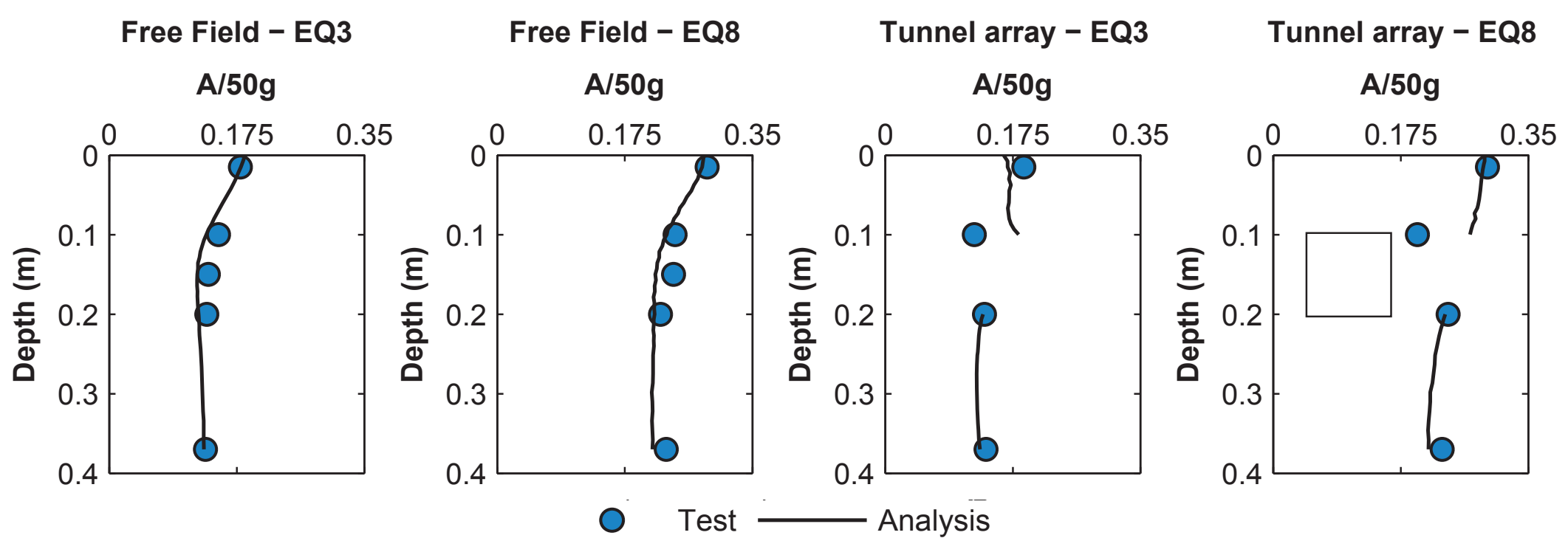


Click here to download Figure: Tsinidisfig08.eps
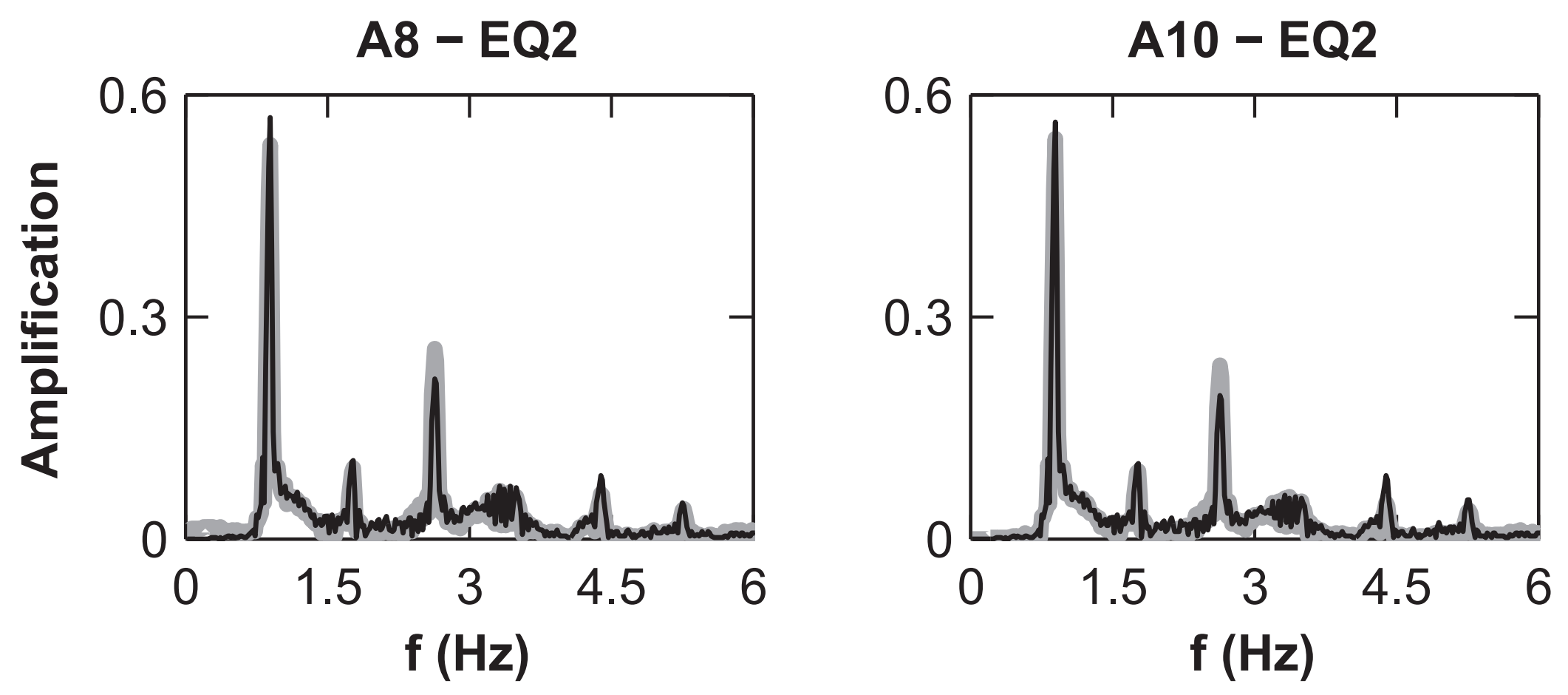


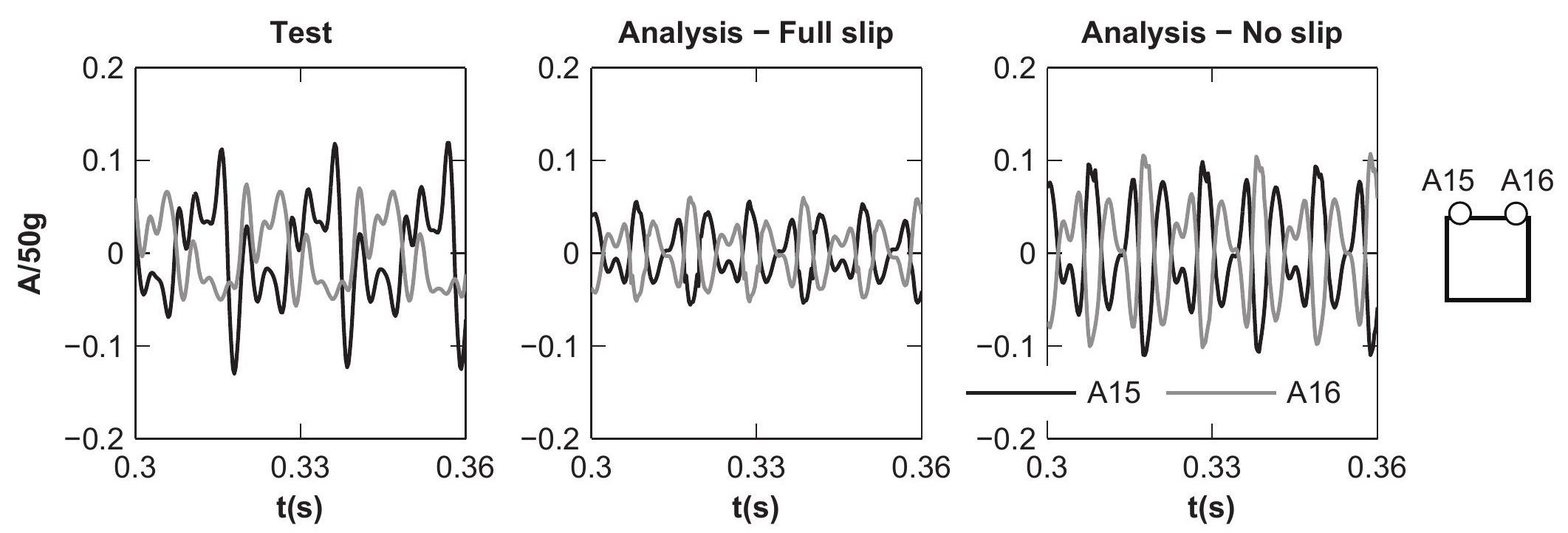


Fig10

Click here to download Figure: Tsinidisfig10.eps
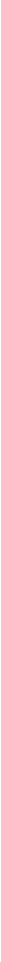
EQ2

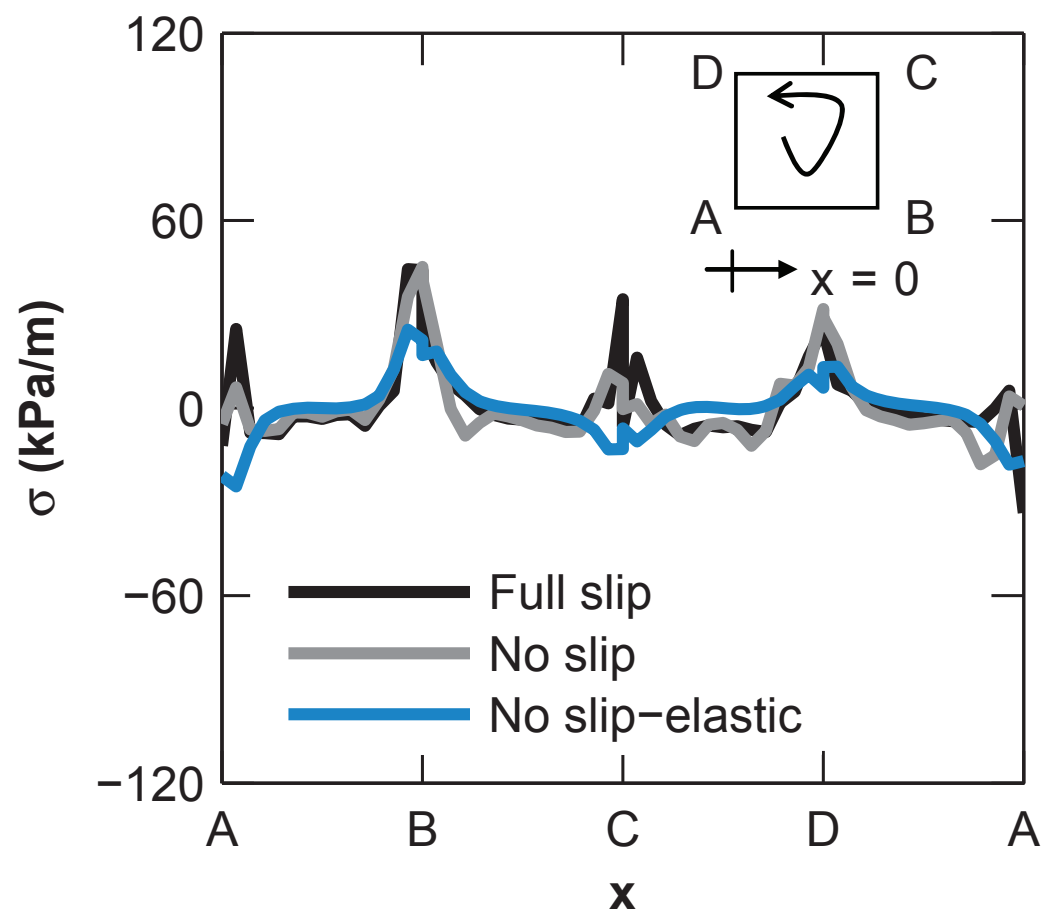

EQ4

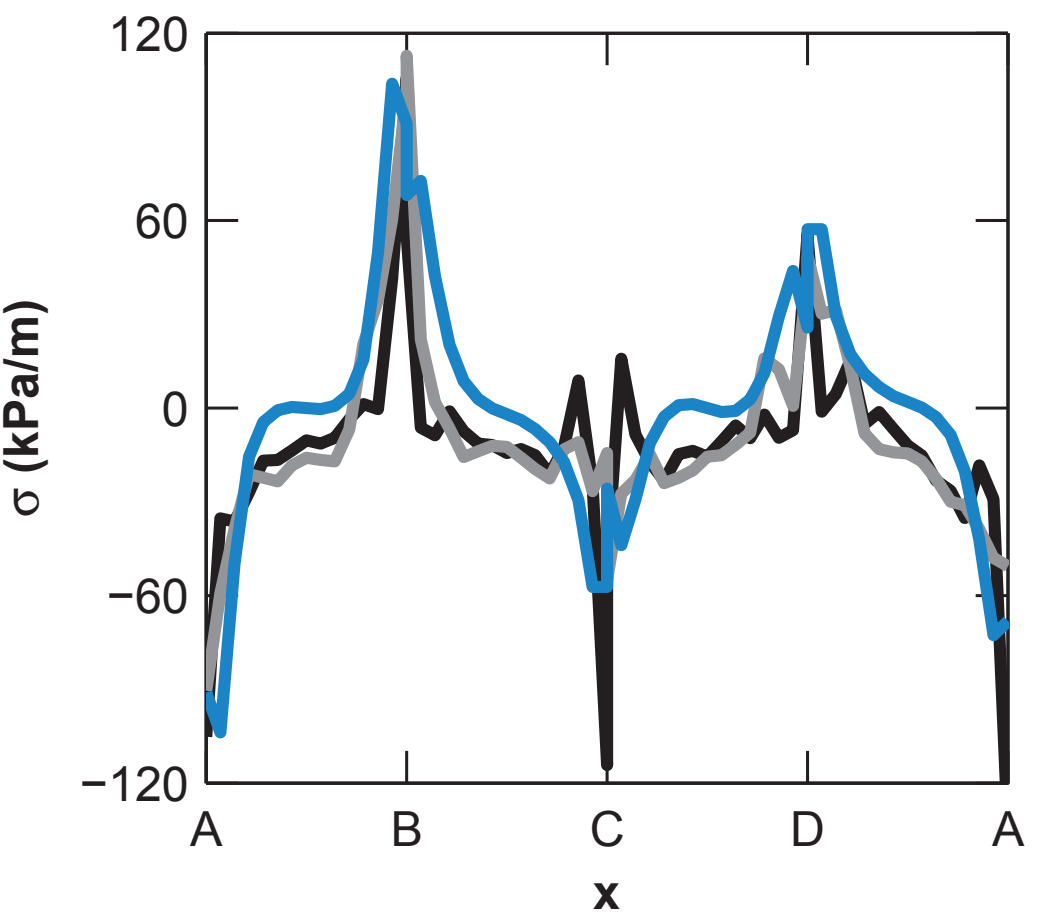


Click here to download Figure: Tsinidisfig15.eps
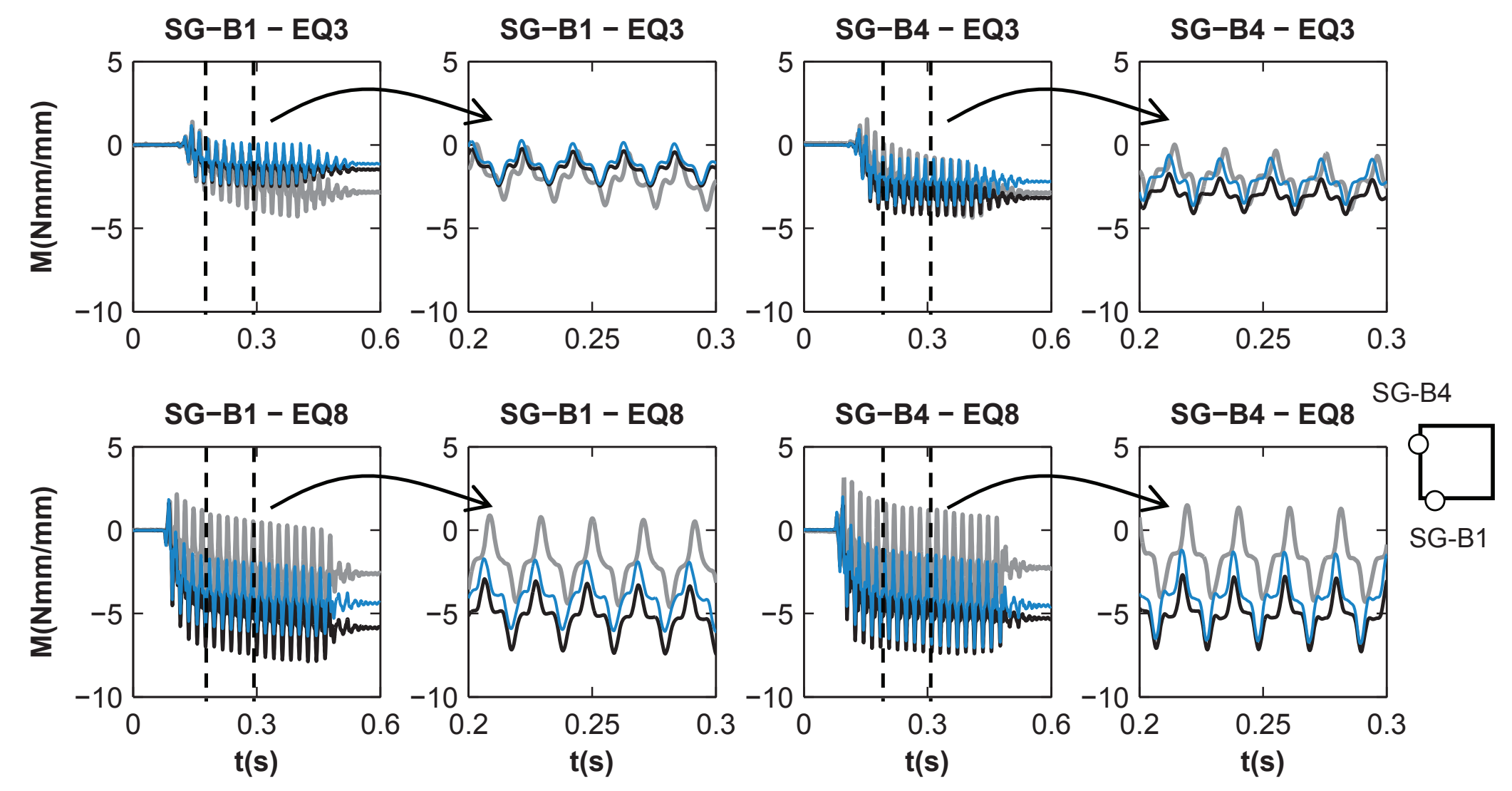
(a)

(a) 20

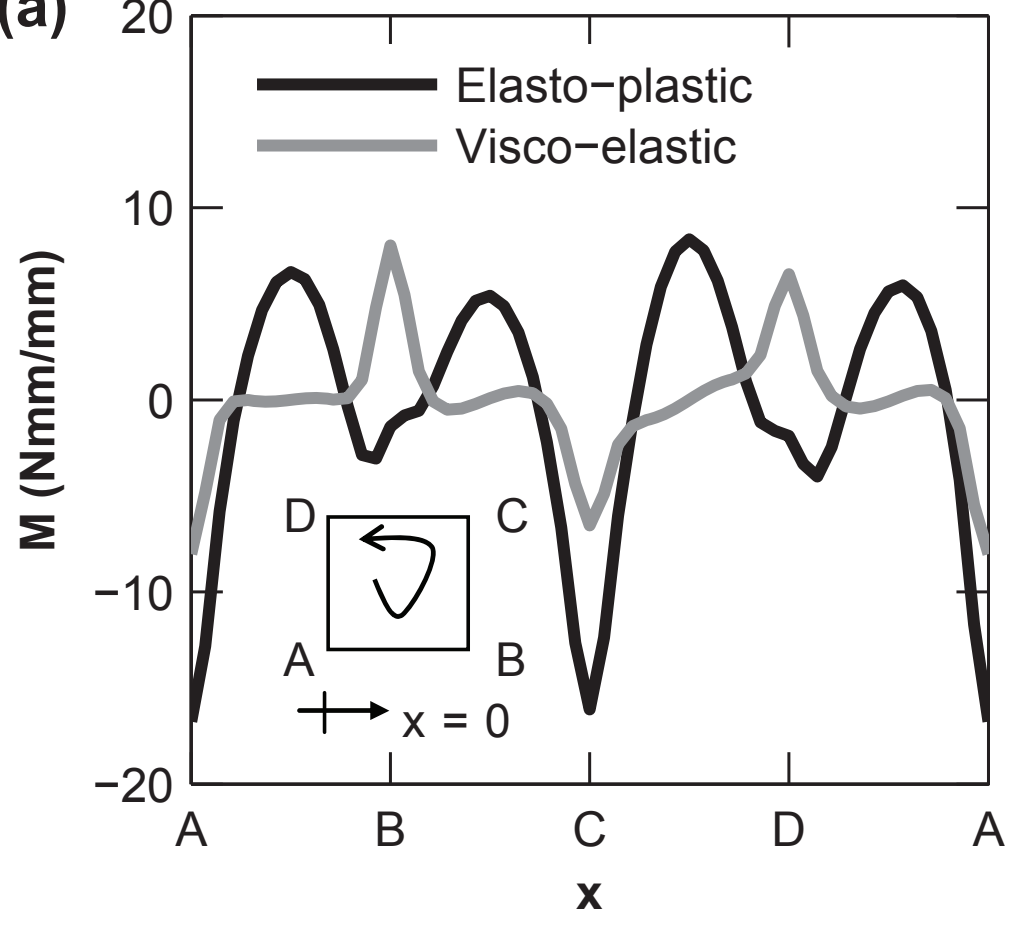

(b) 20

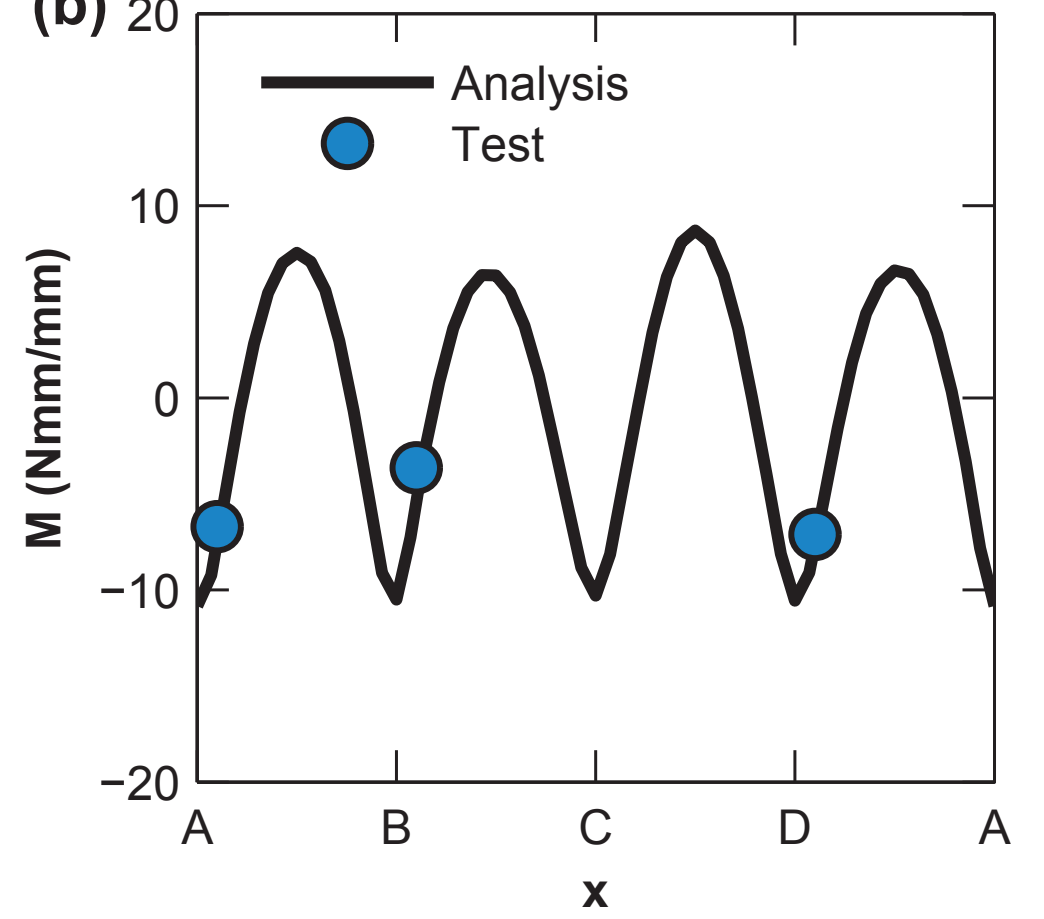




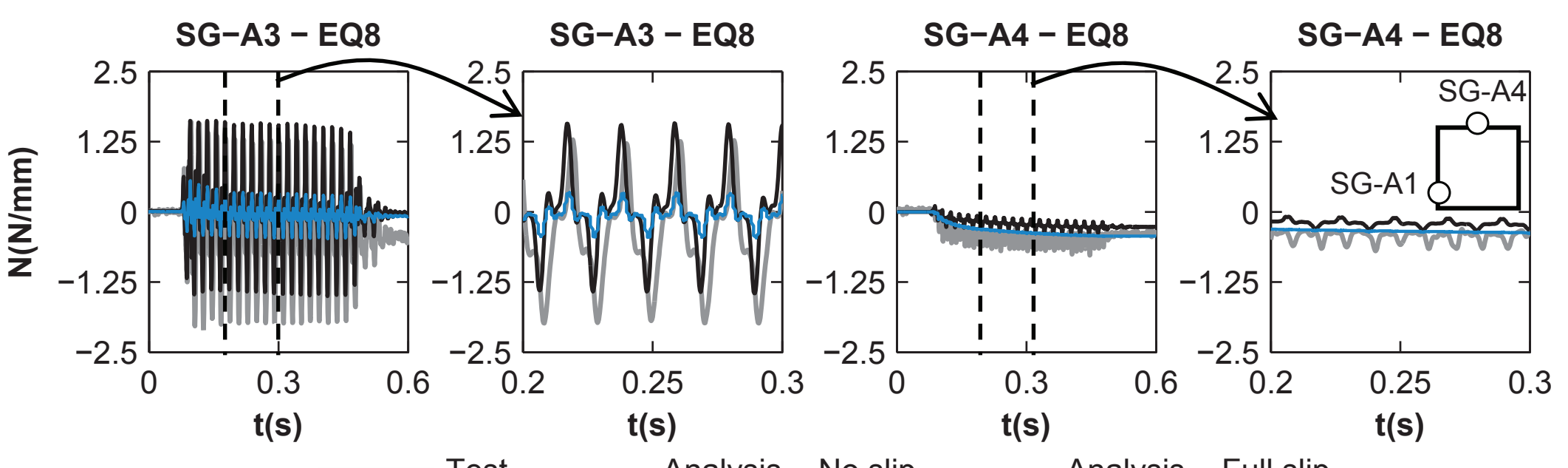

Test $\longrightarrow$ Analysis - No slip $\longrightarrow$ Analysis - Full slip 
(a)

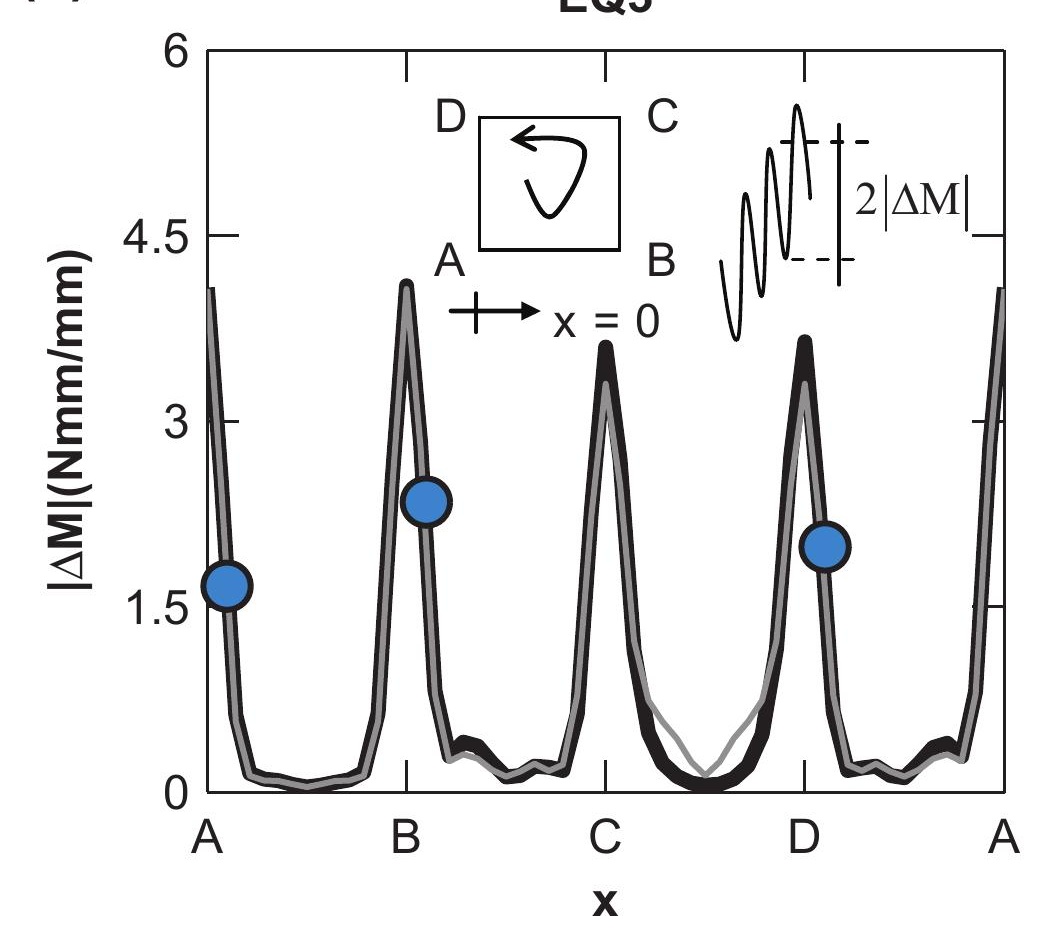

(b)

EQ4

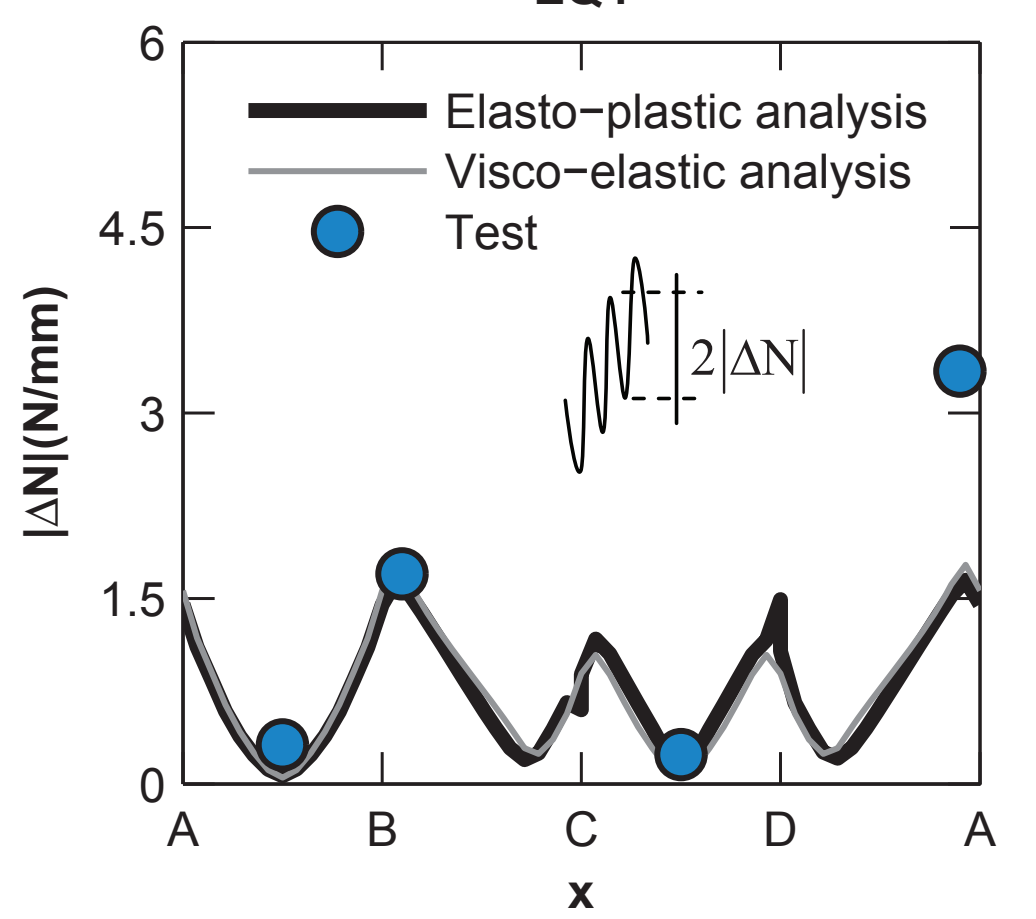


Click here to download Figure: Tsinidisfig19.eps

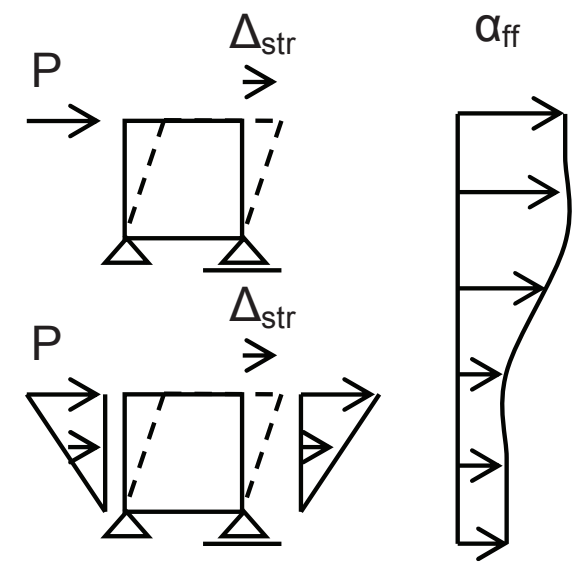

(a)

(b)

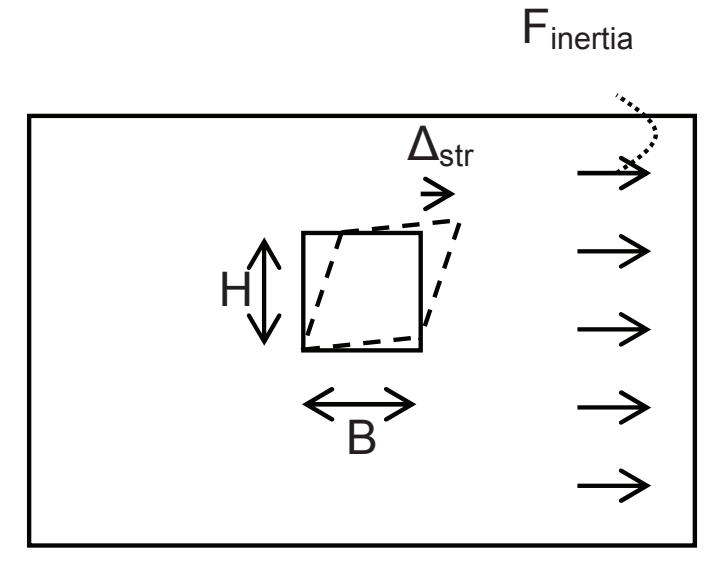

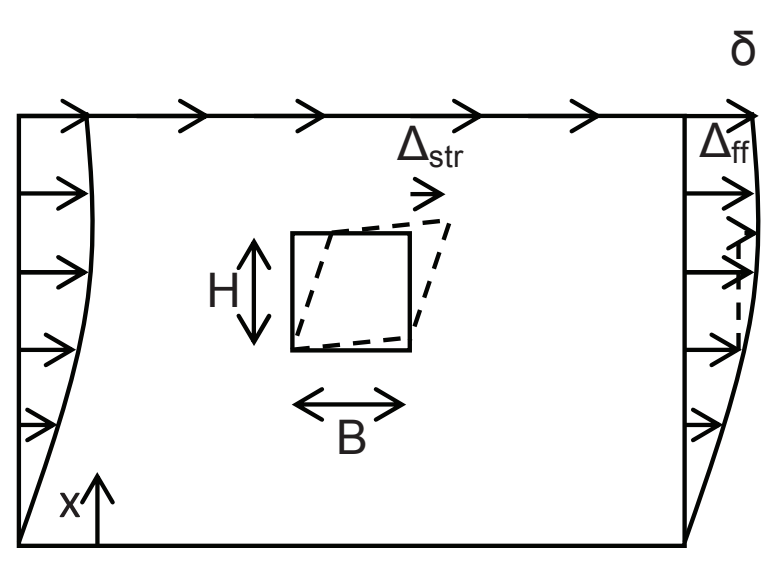

(c) 


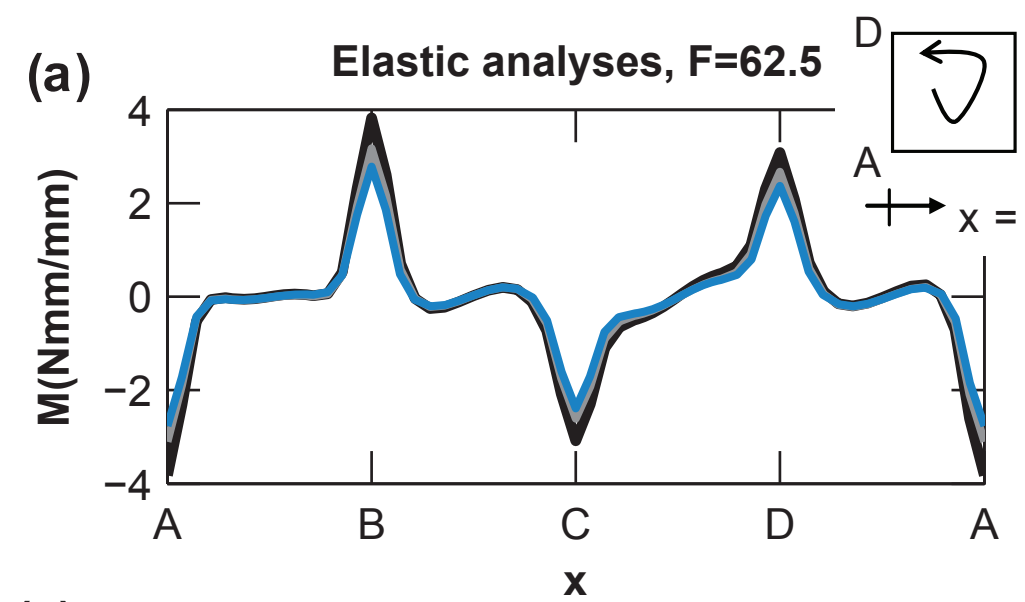

(c)
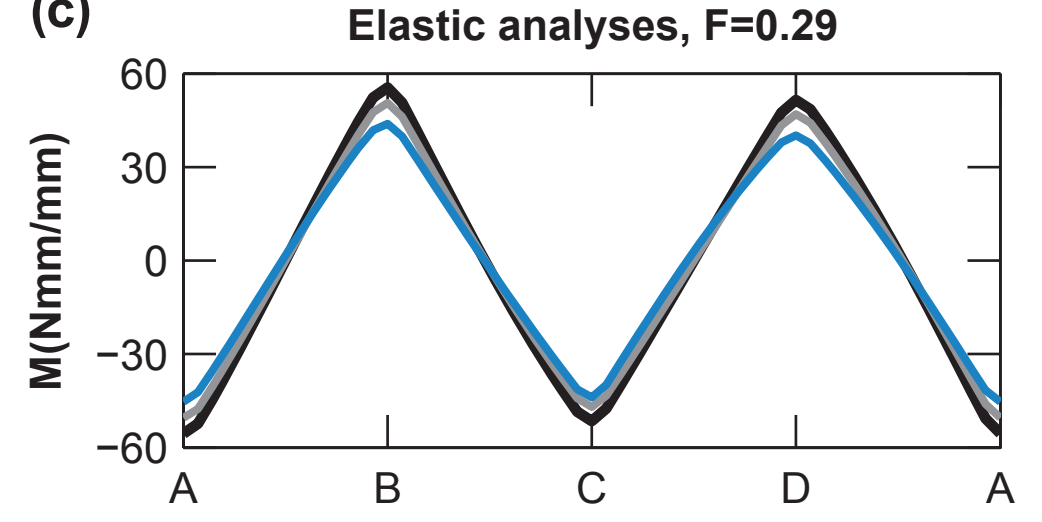

Dynamic analysis

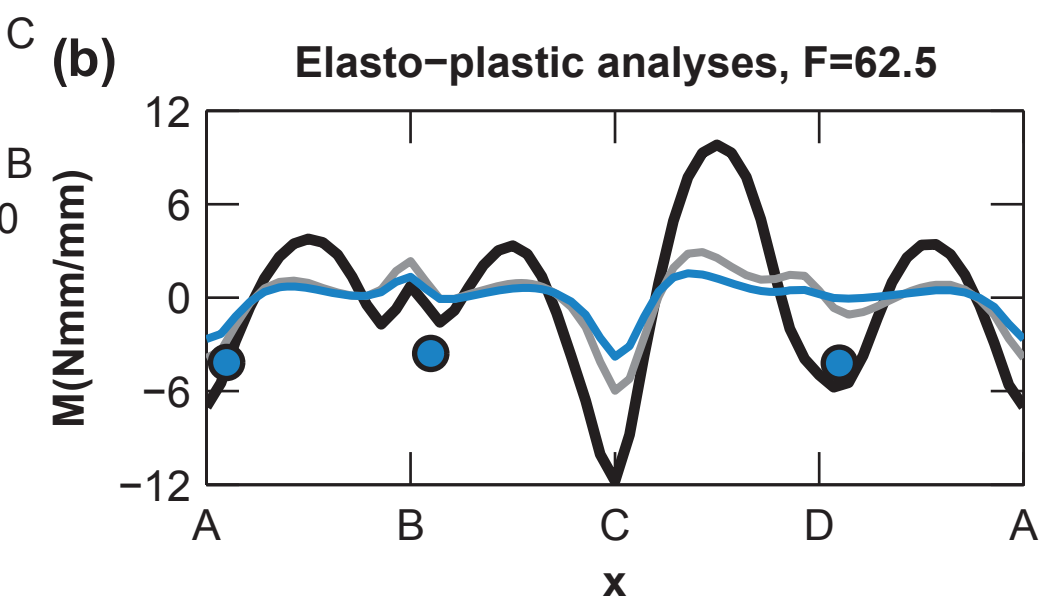

(d) Elasto-plastic analyses, $F=0.29$

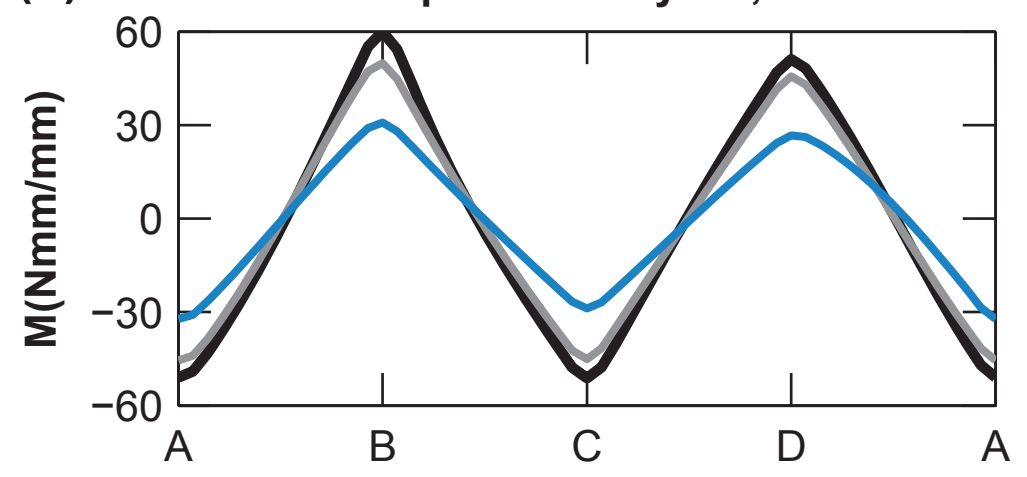

EQL static analysis - force

$\overline{\mathrm{EQL}}$ static analysis - deformation $\quad \mathrm{O}^{-}$Test 


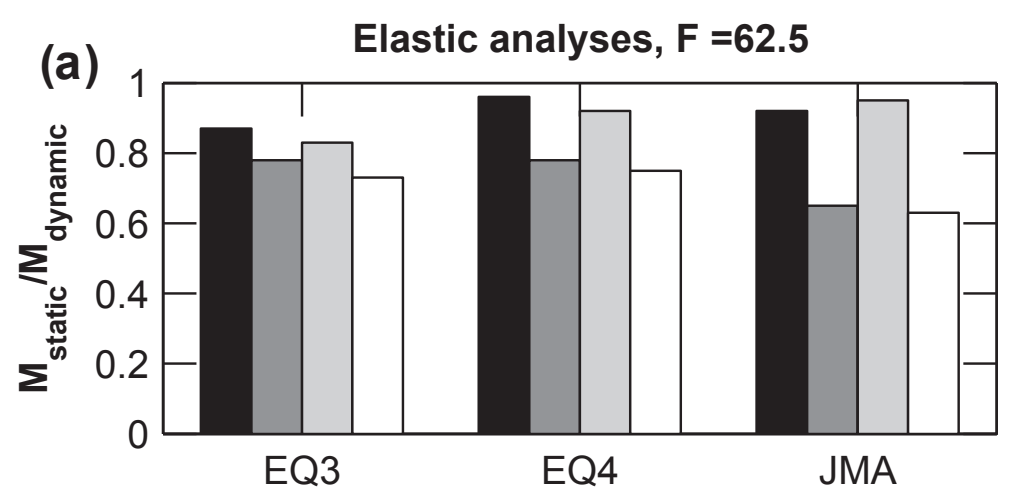

(c)

$\Sigma$

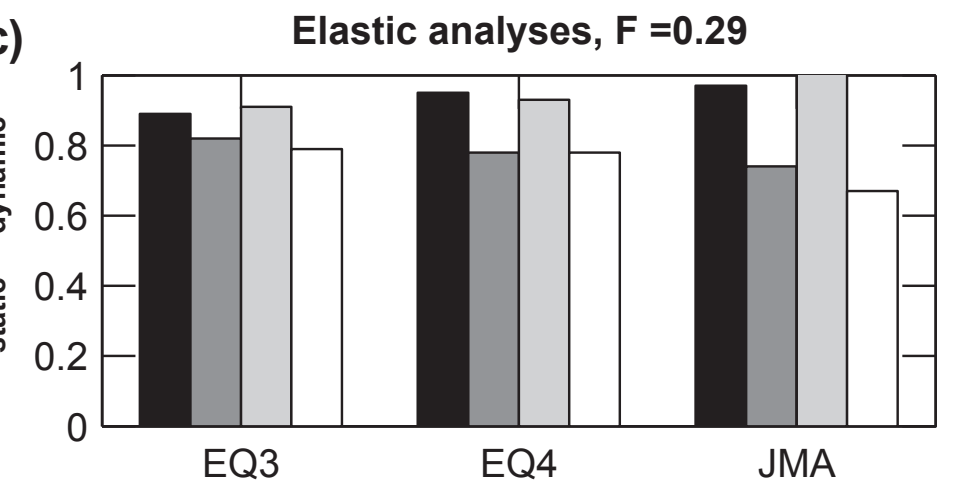

Full slip, force (b)

Elasto-plastic analyses, F =62.5

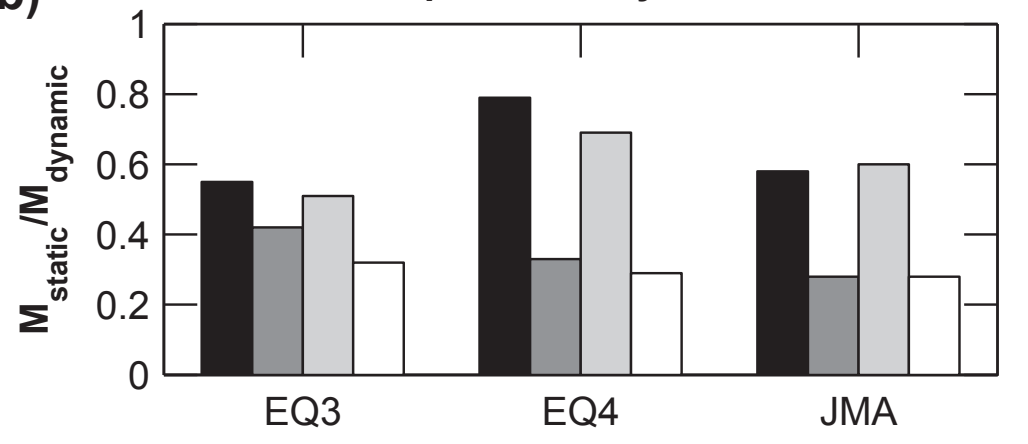

(d)

Elasto-plastic analyses, $\mathrm{F}=\mathbf{0 . 2 9}$

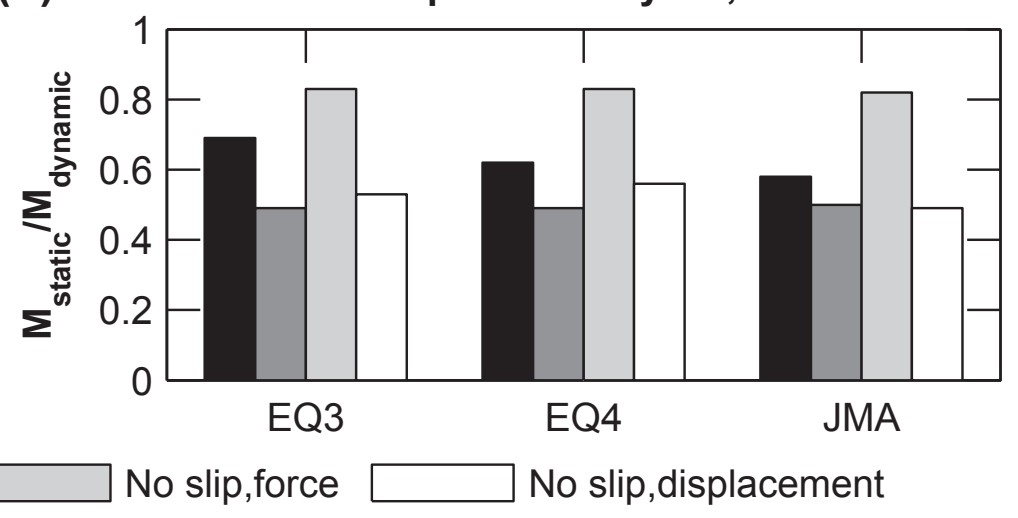

